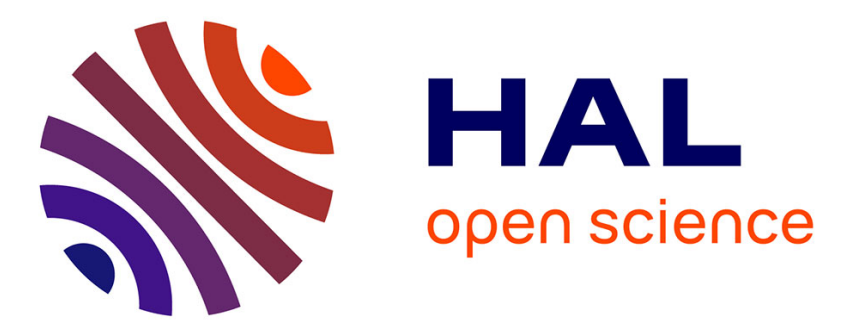

\title{
Aspects of the seasonal variability of the Northern Current (NW Mediterranean Sea) observed by altimetry
}

Florence Birol, Mathilde Cancet, Claude Estournel

\section{To cite this version:}

Florence Birol, Mathilde Cancet, Claude Estournel. Aspects of the seasonal variability of the Northern Current (NW Mediterranean Sea) observed by altimetry. Journal of Marine Systems, 2010, 81 (4), pp.297-311. 10.1016/j.jmarsys.2010.01.005 . hal-00519368

\section{HAL Id: hal-00519368 \\ https://hal.science/hal-00519368}

Submitted on 24 Jan 2022

HAL is a multi-disciplinary open access archive for the deposit and dissemination of scientific research documents, whether they are published or not. The documents may come from teaching and research institutions in France or abroad, or from public or private research centers.
L'archive ouverte pluridisciplinaire HAL, est destinée au dépôt et à la diffusion de documents scientifiques de niveau recherche, publiés ou non, émanant des établissements d'enseignement et de recherche français ou étrangers, des laboratoires publics ou privés.

\section{(ㄷ)(1) $\$$}

Distributed under a Creative Commons Attribution - NonCommercial| 4.0 International 


\title{
Aspects of the seasonal variability of the Northern Current (NW Mediterranean Sea) observed by altimetry
}

\author{
Florence Birol ${ }^{\mathrm{a}, *}$, M. Cancet $^{\mathrm{b}}$, C. Estournel ${ }^{\mathrm{b}}$ \\ a Centre de Topographie des Océans et de l'Hydrosphère, Laboratoire d'Etudes en Géophysique et Océanographie Spatiales (CNRS/CNES/IRD/UPS), 14 avenue Edouard Belin, 31400 Toulouse, \\ France \\ b Pôle d'Océanographie Côtière, Laboratoire d'Aérologie, CNRS, Université de Toulouse, 14 avenue Edouard Belin, 31400 Toulouse, France
}

\begin{abstract}
Altimetry has become a powerful tool to understand the dynamics of the deep-sea ocean circulation. Despite the technical problems encountered in the coastal zone by this observational technique, resulting in large data gaps in those areas, solutions already exist to mitigate this issue and to allow the retrieval of coastal information from existing altimetric data. Using some of these solutions, we have reprocessed a new set of 14.5 years of the TOPEX/Poseidon and Jason-1 satellite altimeter data over the Northwestern Mediterranean Sea, leading to a significant increase in the quantity of available data near coastlines. Time series of geostrophic surface velocity anomalies have been computed from the along-track altimeter sea level anomalies. In this paper, we evaluate the ability of these altimeter-derived currents to capture the main surface circulation features and the associated seasonal variability in the area of interest.

In-situ ADCP current measurements are used to estimate the accuracy of altimeter geostrophic surface velocity anomalies at different locations on the shelf edge. The results indicate good qualitative altimeter performances at seasonal time scales, confirming that altimetry is reliable to observe synoptic variations of the Liguro-Provençal-Catalan Current System. The seasonal evolution of the shelf edge flow is then documented using results from satellite altimetry and from sea surface temperature (SST). The regional picture of the shelf edge circulation that emerges agrees fairly well with previous knowledge (the flow is much stronger during winter than during summer) but also reveals interesting aspects of the coastal current system: (1) the characteristics of the seasonal cycle observed appear highly consistent along the Northwestern Mediterranean shelf break, suggesting a continuous current from the Tyrrhenian to the Balearic Seas, (2) the relationship with the Balearic Current appears somewhat more complex and suggests that its evolution is controlled by another inflow contribution, at least in spring, (3) the seasonal variations of the shelf edge flow over a particular year can show large discrepancies with the averaged picture presented in this study, since large year to year differences are observed.
\end{abstract}

\section{Introduction}

Satellite data are an important component of the ocean observing system. Their obvious advantages are to give a synoptic view of the oceanic conditions and to satisfy criteria in terms of sampling frequency and duration of observations. Amongst them, altimetric data have been intensively used over the last decade for observing and analyzing the large-scale circulation variability in many areas of the world ocean (for example: Wang and Koblinsky, 1996; Fu and Chelton, 2001; Strub and James, 2002a,b). The altimetric sea surface height ( $\mathrm{SSH}$ ) data extends over more than 15 years with a relatively good continuity and consistency between different missions and instruments, and has unique capabilities to provide information about the dynamics of the ocean. However, the usefulness of this type of

\footnotetext{
* Corresponding author.

E-mail address: Florence.Birol@legos.obs-mip.fr (F. Birol).
}

data for observing the coastal ocean is currently under exploited. Even though past studies have shown their potential (Echevin, 1998; Birol and Morrow, 2003; Ridgway and Condie, 2004; Deng et al., 2008), the use of satellite altimetric products in the coastal ocean is challenging because of three types of problems. First, and certainly the strongest limitation, the radar echo itself interferes with the surrounding land, which results in unreliable data within $\sim 5-10 \mathrm{~km}$ of the coastlines (Deng et al., 2002). Second, the standard corrections (e.g. wet tropospheric correction, wave height, high frequency and tide corrections from global models, etc...) applied to the altimeter data are not adapted to the intrinsic characteristics of the coastal dynamics (shorter spatial and temporal wavelengths) and add to the problem of poor quality in altimeter data over shallow waters. As a consequence the precision of the altimeter data decreases dramatically when approaching the coast and the data are usually flagged within $50 \mathrm{~km}$ of the land in products distributed by operational centres. Finally, the space-time sampling of the altimetric satellites is generally too low to capture a wide range of coastal ocean processes (coastal tides and 
high frequency barotropic dynamics, inertial motions, shorter scale eddies and meanders associated with flow instabilities, ...).

In the near future, the new generation of altimetric missions will better fulfil the requirements for coastal observations (AltiKa, SWOT, etc...). But in parallel, we need to develop new approaches to address the problems mentioned above, including data processing strategies dedicated to coastal purposes, to understand the physics represented in the signals (i.e. interpret the coastal SSH data in terms of underlying ocean dynamics, define their usefulness and limitations). We also need to analyze how to use altimetry in combination with other types of coastal observing systems (other satellite observations but also insitu measurement networks or airborne observations) and/or ocean models. Such experience gained from existing altimetric data will guide the design of future missions, and is crucial to optimize both the quality and quantity of altimetric data records in the coastal zones.

Substantial efforts have been made by the scientific community to address these questions. Based on different approaches, some solutions have already been proposed to improve the quality, availability and resolution of altimetric data near and above continental shelves (Vignudelli et al., 2005; Deng and Featherstone, 2006; Bouffard et al., 2008a; Saraceno et al., 2008; Roblou et al., in press). As an example, authors have shown (Volkov et al., 2007; Bouffard et al., in press) that the use of an accurate tidal model over continental shelves highly improves the quality of the altimeter observations. In this context, an advanced altimetric data processing software named X-TRACK has been developed (Roblou et al., in press), and experimentally implemented at the Centre for Topographic studies of the Ocean and Hydrosphere (CTOH). It has been used on dedicated oceanic regions. The improvement resulting from this processing tool is obvious, both in terms of error reduction and data availability near the shelf (Vignudelli et al., 2005; Bouffard et al., 2008b, in press). Even if a lot remains to do, previous studies show that the corresponding reprocessed satellite data are able to capture characteristics of the coastal dynamics, offering the opportunity to document the variability of various dynamical processes at different time scales (Vignudelli et al., 2005; Bouffard et al., 2008b; Durand et al., 2008; Bouffard et al., in press).

In this study, we will address the question of what can be observed in the case of the Northwestern Mediterranean Sea boundary circulation. We will examine satellite altimetry-derived fields on a regional basis, and analyze what new insights can be gained using the retrieved information compared to past studies, satellite SST fields and in-situ measurements. This region is interesting for such an exercise because it has been the site of previous intensive in-situ campaigns, providing a relatively good knowledge of the main characteristics of the surface current system (for example: Millot, 1987; Astraldi et al., 1990; Castellón et al., 1990; Millot, 1987; García et al., 1994; Sammari et al., 1995).

The Northwestern Mediterranean Sea appears to be a dynamical entity. The "Northern Current", also known as the Liguro-ProvençalCatalan Current (hereinafter LPC) is the surface part of the thermohaline circulation of the Mediterranean Sea. It is formed by the return branch of the cyclonic circulation of the Western Mediterranean Sea (Herbaut et al., 1998; Béranger et al., 2004) and is reinforced by the wind stress curl over the Liguro-Provençal Basin (Herbaut et al., 1997). The LPC results from the merging, in the Ligurian Sea, of two currents flowing northward on both sides of Corsica, the Eastern Corsican Current (ECC) and the Western Corsican Current (WCC) (Fig. 1). The LPC then flows cyclonically along the coasts of Italy, France and Spain (Millot, 1991). This boundary current is a permanent feature in a band $\sim 30-50 \mathrm{~km}$ wide and is associated with a marked shelf/slope density front. In the Channel of Ibiza, the LPC splits in two parts. The first one crosses the strait and flows toward the Algerian Basin; the second one recirculates eastward along the Balearic Islands, forming the Balearic Front before reaching the Corsica Island (Castellón et al., 1990), resulting in a cyclonic gyre in the middle of the Northern Basin. Several driving mechanisms and processes are responsible for the circulation patterns and variability in the different sub-basins of the studied area (thermohaline circulation

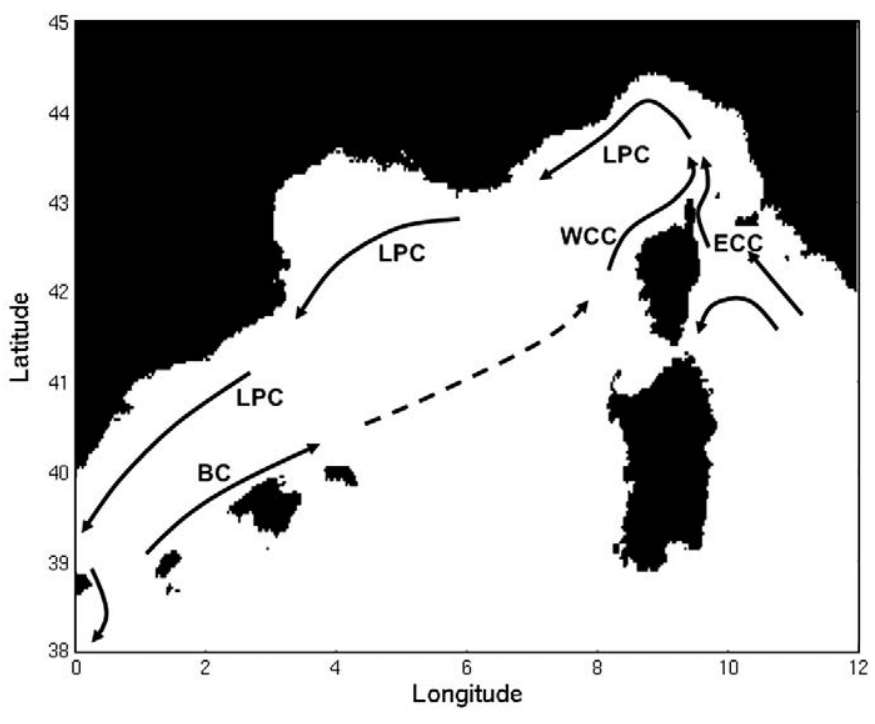

Fig. 1. Schematic view of the major ocean circulation features in the Northwestern Mediterranean Sea.

at the basin scale, wind, deep water formation, frontal instabilities, topographic effects).

Some characteristics of the flow structure are highlighted from the direct current and hydrographic measurements (PROS-6, DYOME, PRIMO, CANALES, WMCE and MEDOC cruises, ...) made at different locations and periods of time along the path of the LPC. Past studies generally describe the current as a complex system, with important spatial and temporal variability (Millot, 1991; Albérola et al., 1995; Pinot et al., 2002). Large cruise to cruise variability of the slope circulation has been observed. However, it displays a clear seasonal variability (Albérola et al., 1995; Millot, 1995; André et al., 2005), with a maximum flux during winter and spring. In winter, the LPC Current is expected to be deeper, narrower, baroclinically unstable and tends to flow closer to the slope (Crépon et al., 1982; Millot, 1991). In this study, we will analyze whether the altimeter fields reprocessed with a coastally oriented strategy can be used to give a synoptic view of the seasonal variability of the rather narrow coastal surface circulation in the Northwestern Mediterranean Sea. Of particular interest is the long time series of these synoptic satellite observations (more than 14 years are used in this study) that provide a relatively good climatological view of the current system, as well as its seasonal/interannual variability.

This article is organized as follows: In Section 2, we present the geostrophic current anomalies computed from altimetric data, as well as the in-situ current meter and SST data and the derived climatologies that are used to validate and interpret the results. In Section 3, the satellite derived and in-situ current measurements are compared. A regional analysis of the seasonal evolution of the circulation observed near the shelf break is proposed in Section 4 and a discussion of the results concludes this study in Section 5 .

\section{Data}

\subsection{Geostrophic current anomalies derived from altimetry}

We use altimeter data from Geophysical Data Records (GDRs) provided by AVISO (1996) for both TOPEX/Poseidon (T/P hereinafter) and Jason-1 missions. The whole data set has been reprocessed along the tracks with the X-TRACK software (Roblou et al., in press) at a $1 \mathrm{~Hz}$ rate (6-7 km), from cycle 17 (28 February 1993) to cycle 364 (1 August 2002) for T/P, and from cycle 22 (11 August 2002) to cycle 213 (28 October 2007) for Jason-1 data. The objectives of this software are to improve both the quantity and quality of altimeter estimates in coastal regions by reprocessing a posteriori the GDRs delivered by operational centres, In 
brief, it consists of redefining the data editing strategy to minimize the loss of data during the correction phase, using improved local modelling of tides and short-period ocean response to wind and atmospheric pressure forcing where possible and using an optimal, high resolution, along-track vertical reference surface. For details, the reader is referred to the paper by Roblou et al. (in press) and to the Annex section of Durand et al. (2008). An evaluation of the resulting data characteristics has demonstrated the efficiency of the X-TRACK strategy in restoring much more near-coastal SSH measurements than classical processing systems (Vignudelli et al., 2005; Bouffard et al., 2008b; Durand et al., 2008; Bouffard et al., in press). The two altimeter missions mentioned above have the same 10-day period and use the same reference ground tracks. For the computation of corrected SSH data, the standard geophysical corrections provided by AVISO (1996) are applied to altimeter ranges, except for the geophysical corrections (tides and high frequency signal aliasing) which have been computed using the regional barotropic Mog2D/TUGO-Medsea model outputs (Carrère and Lyard, 2003; Mangiarotti and Lyard, 2008) instead of state-of-the-art global models. To integrate the data, a relative mean bias between T/P and Jason- 1 has been computed over the Jason-1 validation phase and is applied to the Jason-1 altimeter range. As the resolution and accuracy of available geoid models are not adequate at mesoscale wavelengths (LeGrand, 2005), conventionally, only sea level anomalies (SLA) are used, i.e. the part of sea surface height due to the ocean variability. The mean ocean component due to steady currents must be retrieved by independent data. In this paper, we use only SLA which have been obtained by subtracting an along-track mean SSH profile, computed by averaging the altimetric SSHs over the entire duration of our time series. Along-track and cross-track geoid slopes have been used as a correction to refer all SLA data to equally sampled reference points along the nominal ground track (Legresy et al., 2006). In order to reduce the noise, a low-pass Loess filter (Cleveland and Devlin, 1988) with a 20-km cut-off wavelength was applied to the alongtrack SLA. This finally forms at each altimetric reference point a long time series of 540 samples with a 10-day time resolution.

The T/P and Jason-1 ground track sections used for this study were chosen because they cross the LPC system at different locations as shown in Fig. 2. The 200-m, 1000-m and 2000-m isobaths computed from the ETOPO2 model (version 2) are superimposed. The tracks are separated by $\sim 245 \mathrm{~km}$. Assuming geostrophic balance, the cross-track anomalous surface geostrophic velocity (ASGV hereinafter) can then be calculated from the along-track gradient of SLA.

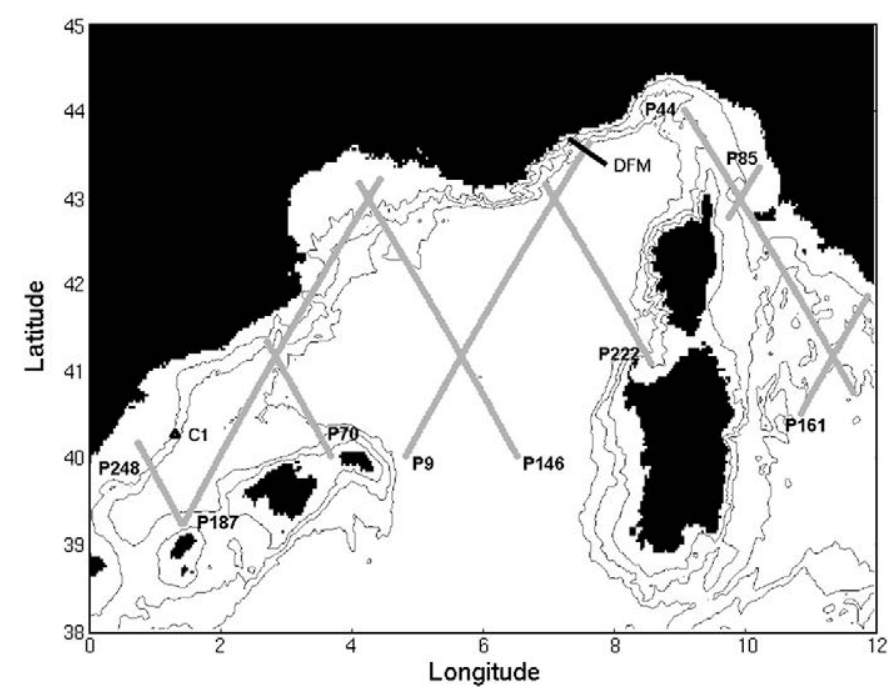

Fig. 2. Distribution of selected $\mathrm{T} / \mathrm{P}$ and Jason-1 tracks over the Northwestern Mediterranean Sea. The 200-m, 1000-m and 2000-m isobaths are shown. The locations of available independent current measurements are also indicated (a solid triangle for the $\mathrm{C} 1$ mooring and a bold line for the DFM ADCP transect). Bathymetry is from ETOPO2v2 Global Gridded 2-minute Database.
Note that only the velocity component perpendicular to the altimeter pass is reliable from along-track altimetric data. The higher the angle between the cross-track direction and the local axis of the current system, the lower is the ability of altimetric data to locally capture the current variability (Morrow et al., 1994). However, since the coastal currents flow on average along the continental shelf edge, from Fig. 2, it is clear that some tracks $(248,70,146,222$ and 161) of the T/P and Jason-1 missions are approximately perpendicular to the boundary currents.

In order to study the seasonal current variability, we have removed the intense transient events which can be very important within the study area (Millot, 1991; Albérola et al., 1995; Estournel et al., 2003). For this, we have filtered the data with a low-pass Loess filter using a 30 day cut-off period. Moreover, the convention we have chosen is that current anomalies are positive to the left of the track (when looking to the north). Therefore, along the northern branch of the cyclonic LPC, positive (negative) values mean an increase (decrease) of the current velocity; along the southern recirculation branch, positive (negative) values mean a decrease (increase) of the current velocity. The number of derived ASGV data over the period of interest was compared with the one derived from the regional AVISO product (http://www.aviso. oceanobs.com/en/data/products/sea-surface-height-products/index. html). In Fig. 3, we can clearly observe that significant information is recovered by using a coastally oriented processing strategy, compared to an open-ocean one. This is particularly true in the Balearic Sea, near the shelf break of the Ligurian Sea and in the northern Tyrrhenian Sea where large data gaps exist in classical altimetric products (also shown by Bouffard et al., 2008b and Vignudelli et al., 2005). The first stage of validation was to assess the quality of the recovered information. As shown in the next sections, there appears to be a very good consistency between the data located over and off the continental shelf.

Finally, along each altimetric track, a monthly climatology of ASGV was constructed by simply averaging the corresponding monthly values of the long-term time series (1993 to 2007). The resulting information will be discussed in Section 4. However, note that altimetry only allows us to observe the geostrophic current anomalies. As a consequence, only the variability of the circulation will be discussed in this study.

\subsection{Independent current measurements}

In order to quantify the accuracy of the altimetric-derived geostrophic currents in the near-shore region, we have used 1) the measurements from a subsurface current meter moored on the Catalan shelf break (mooring $\mathrm{C} 1$ on Fig. 2) in the frame of the Spanish FANS and YOYO projects, and 2) current measurements made in the Ligurian Sea from a ship-mounted acoustic Doppler current profiler (ADCP) (these measurements are made in the framework of the BOUSSOLE and DYFAMED projects, the corresponding mean transect is noted DFM and indicated on Fig. 2). Note that the locations of in-situ measurements and altimeter ground tracks do not coincide with each other. The altimeter computed currents include only the anomaly of the geostrophic component that is perpendicular to the track. In addition, the temporal and spatial scales resolved are also different (see below). Therefore, smoothing in time and/ or space has been applied to the independent data, and comparisons will be made in terms of observed current anomalies.

The current meters offshore the Catalan coast are rotor based Aanderra RCM7 with a 30-minute sampling frequency. A total of 3 current meters were deployed over the period stretching from 10 March 1997 to 12 May 1999 on a mooring located on the coastal edge of the LPC Current. Local water depth was $600 \mathrm{~m}$ and current meters were positioned near $100 \mathrm{~m}, 300 \mathrm{~m}$ and $500 \mathrm{~m}$ depth (Jorda, 2005). The distance between C1 location and track 248 is around $55 \mathrm{~km}$. Since altimetry observes the surface current variations, the data we use in this study come from the shallowest instrument at the 100-m depth (below the Ekman layer). Spurious or unavailable data result in large gaps in the time series before 25 March 1998 . The velocities have been rotated by $60^{\circ}$ so that the $\mathrm{x}$ component represents the along slope direction. The time 

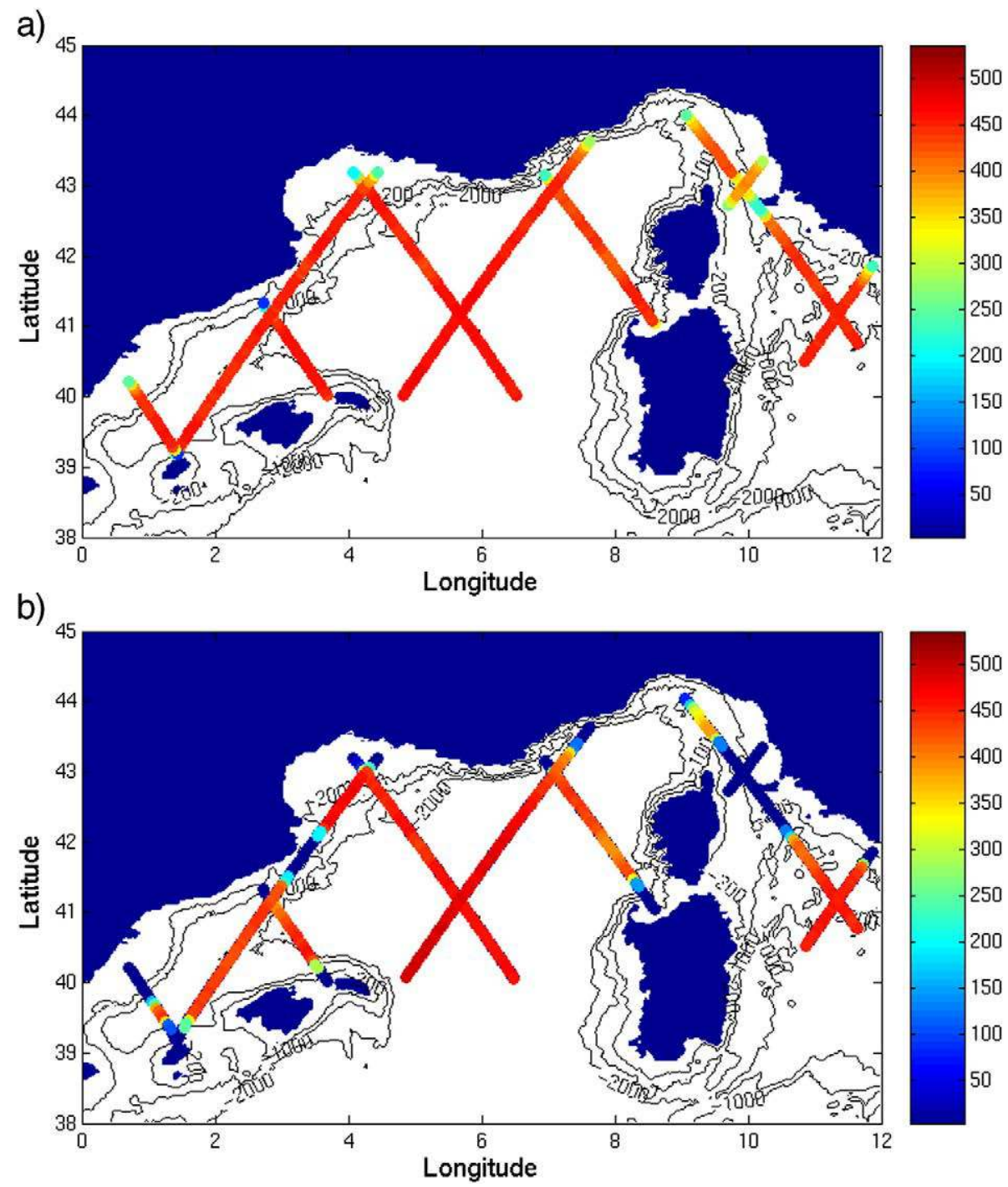

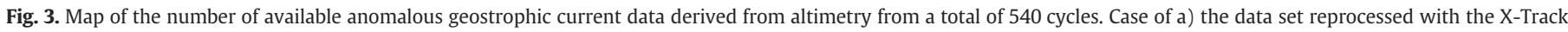
software and b) a classical product. The $200-\mathrm{m}, 1000-\mathrm{m}$ and $2000-\mathrm{m}$ isobaths are highlighted.

series of the resulting velocity anomalies are presented in Fig. 4a (grey curve), after removing tidal and inertial motions with a 48-hour low-pass filter and the temporal mean velocity (approximately $10 \mathrm{~cm} \mathrm{~s}^{-1}$ to the west). Short-period fluctuations, consisting of alternating currents with periods of a few days is the primary source of variability (a complete analysis of this short-term variability is beyond the scope of this paper and can be found in Jorda, 2005). The temporal sampling of T/P and Jason-1 missions does not allow us to resolve this high frequency variability. For comparison with altimeter data, a low-pass 30-day Loess filter has then been applied (Fig. 4a, black curve), so that the in-situ current information is consistent with the filtered ASGV computed from altimetry.

Additionally, since 2000, a large number of ADCP current measurements have been collected by the French R/V Thetys II during very frequent cruises between the French coast and the DYFAMED and BOUSSOLE sites (located in the central Ligurian Sea). Fig. 2 shows the corresponding ship transect. Processed and validated data were obtained from the INSU-DT data service center (http://saved.dt.insu.cnrs.fr/). A total of 235 vertical sections of horizontal currents in geographical coordinates are provided between $8 \mathrm{~m}$ and $240 \mathrm{~m}$ depth from January 2000 to October 2007; measurements were made using a pulse and vertical bin length of $4 \mathrm{~m}$. Since the ADCP data are instantaneous velocities and include ageostrophic parts such as tidal current, internal waves and wind-driven surface current, we adopted smoothing processes in time. The data were first gridded with a $2 \mathrm{~km}$ horizontal bin size along a chosen coast to DYFAMED site reference transect (named DFM on Fig. 2). The bin size was chosen as smallest as possible with practical considerations for sampling density. Ship tracks located outside the chosen grid boxes as well as incomplete transects were eliminated, leading to a total of 119 selected transects. For each bin, the eastward and northward components of the velocity were averaged between $20-\mathrm{m}$ and 100 -m depth and only the current magnitudes are used in this study. For each selected transect, the maximum LPC current magnitude observed was determined from the depth-averaged data. In order to filter out short-term fluctuations, the information collected was then synthesized in a monthly climatology of the LPC Current amplitude. Table 1 lists the temporal distribution of the number of transects included in the calculation as a function of month. Given that the data density is highly heterogeneous, the results will be discussed only in terms of seasonal tendencies. Moreover, for each month, the standard deviation of the maximum current magnitude (20 to $100-\mathrm{m}$ depth) is also provided (Fig. 5).

\subsection{Sea surface temperature}

A sequence of AVHRR (Advanced Very High Resolution Radiometer) sea surface temperature (SST) composite images was obtained from the DLR EOWEB - Earth Observation Information Service (http://eoweb.dlr. de). In this study we use a time series data set that covers the period 
a)

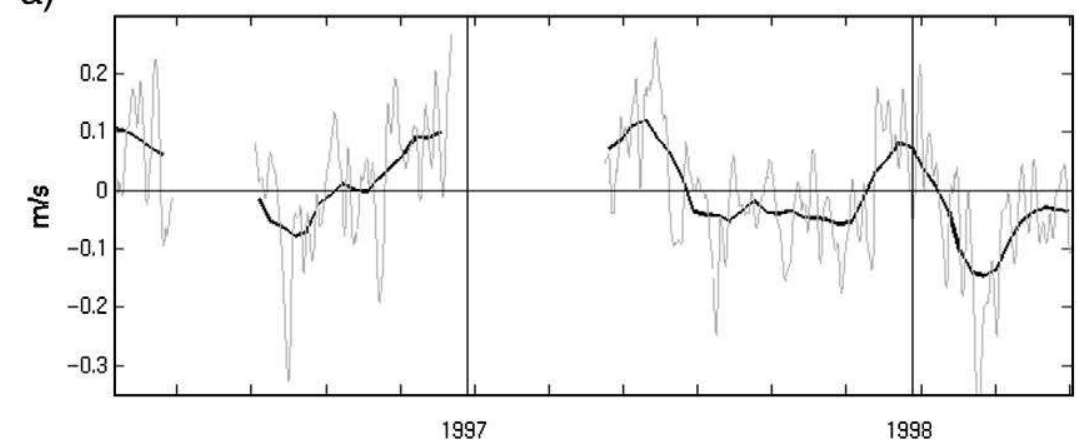

b)
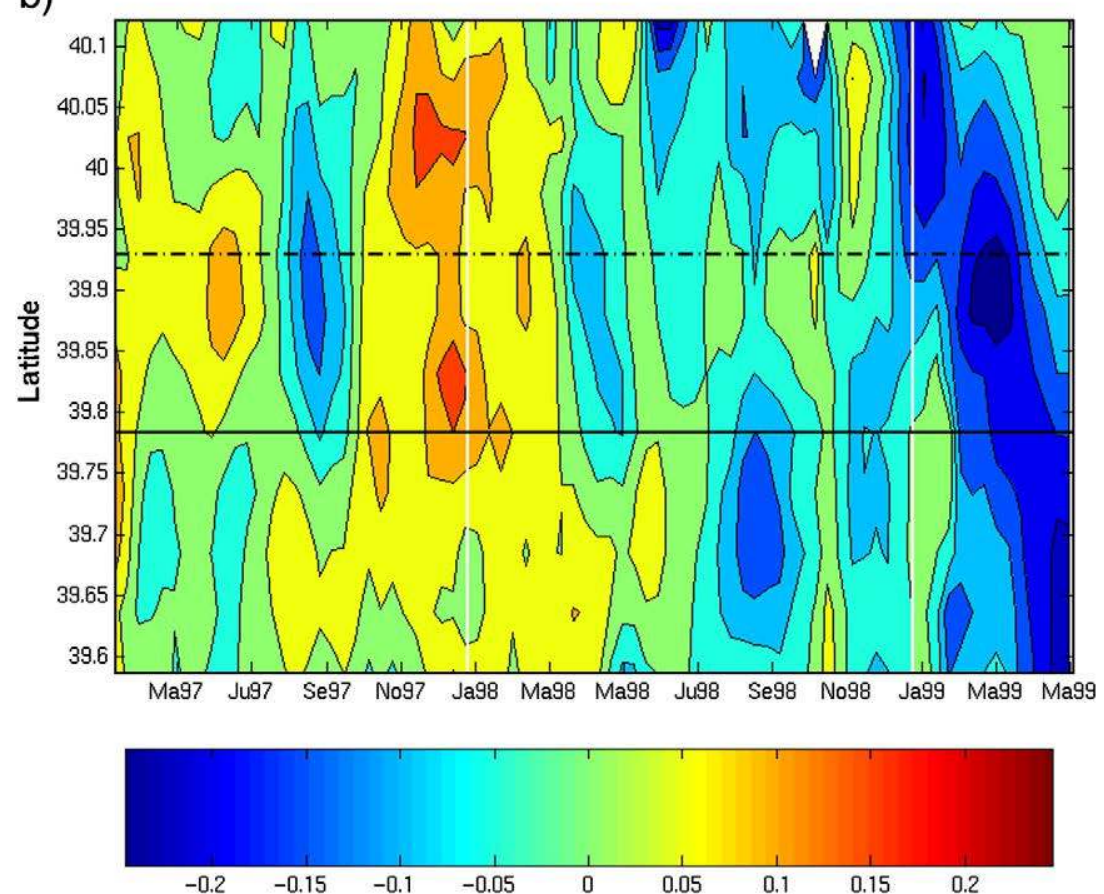

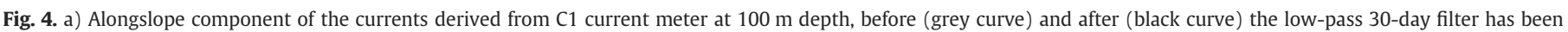

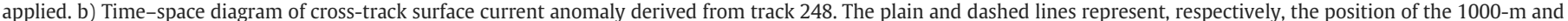
200-m isobaths.

1998-2007 and has been generated from NOAA images using a weekly compositing period. The images have a spatial resolution (pixel size) of $1.1 \mathrm{~km}$. The temperature has a resolution of $0.125^{\circ} \mathrm{C}$. The accuracy is $0.5^{\circ} \mathrm{C}$. A monthly SST climatology was constructed by simply averaging the corresponding monthly values of the time series.

\section{Comparison between altimetric and independent current measurements}

\subsection{Comparison on the Catalan shelf break}

For validation purposes, the filtered altimetric current anomalies along track 248 have been first compared to the in-situ current measurements obtained at $\mathrm{C}$, filtered using a low-pass Loess filter

Table 1

Mean number of transects per month.

\begin{tabular}{llllllllllll}
\hline Jan & Feb & Mar & Apr & May & Jun & Jul & Aug & Sep & Oct & Nov & Dec \\
\hline 6 & 13 & 11 & 23 & 13 & 8 & 9 & 2 & 8 & 12 & 9 & 5
\end{tabular}

with a 30 day cut-off period (Fig. 4, black curve). To facilitate the comparison, the mean value of the altimetric ASGV over the period of $\mathrm{ADCP}$ measurements and the mean velocity measured at $\mathrm{C} 1$ were removed. Positive (negative) values indicate a southwestward (northeastward) flow anomaly. The original in-situ data show that the LPC flows southwest during all the measurement period, except in February-March 1999, tending to confirm the continuity of the LPC system most of the time (Millot, 1999; Jorda, 2005), feature usually not reproduced by ocean numerical models (Herbaut et al., 1996, 1997; Demirov and Pinardi, 2002).

The CANALES experiment (based on repeated hydrographic casts, mooring time series and satellite sea surface temperature measurements) and other studies carried out during the same time period (1996-1998) have shown the presence of a number of mesoscale eddies often stalled for several weeks or months in the southern and northern part of the Balearic Sea, which produce a highly fluctuating circulation, resulting in retroflections or in lateral shifts of the main currents axis (Tintore et al., 1990; Pinot et al., 2002; Echevin et al., 2003; Rubio et al., 2005). Visual inspection of Fig. 4b shows that significant differences can be observed along track 248 between the northern and southern edges of the Catalan shelf break (defined hereinafter as the section of the track located between the $200-\mathrm{m}$ and the $1000-\mathrm{m}$ isobaths), especially in 1998 . It is 
a)

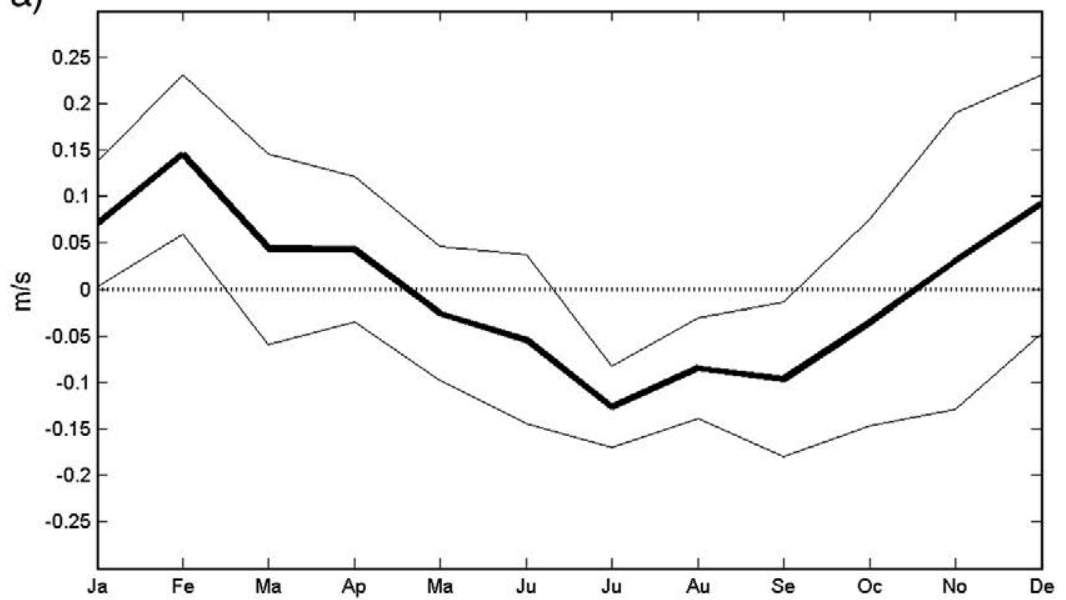

b)

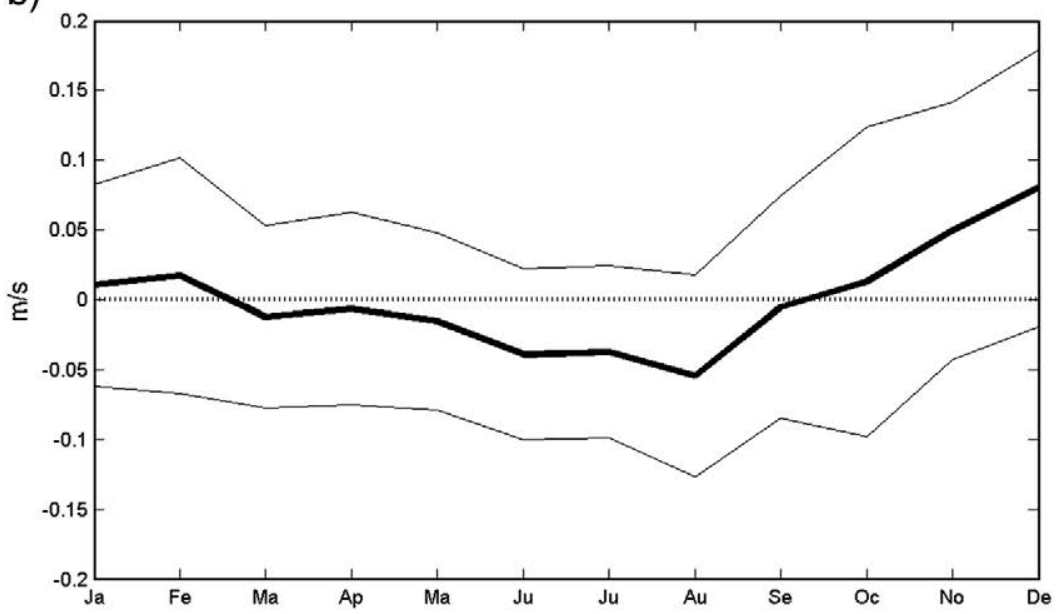

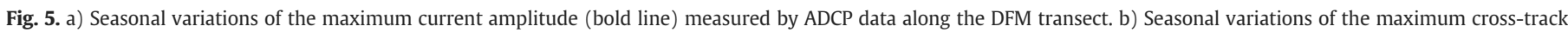
current anomalies derived from track 222 close to the northern end of the track. Monthly standard deviations are also shown for both data sets (thin line).

clear that lateral shifts of the axes of the coastal current or mesoscale structures will largely influence the flow variations recorded at $\mathrm{C} 1$ or along track 248, thus complicating this comparison exercise.

Important variations appear at seasonal scales in both the altimetric and in-situ current fields. In 1997, the flow variations reflect quite well the average picture of the LPC Current (Béthoux, 1988; Font et al., 1988; Pinot et al., 2002). In both time series, the intensity of the coastal current decreases at the end of the spring period to reach a minimum in August, and then increases again in fall. The maximum of the acceleration is observed in December in the altimetric-derived current field. This intensification in winter has also been reported during the CANALES experiment (Pinot et al., 2002). Along track 248, the seasonal variability is maximum over the shelf break.

In Fig. 4b, at the beginning of 1998, the southwestward flow located over the shelf break rapidly decreases and, during the rest of the year, a series of weak transient events rather than a seasonal signal is observed over the continental slope. Unfortunately, the current meter record suffers from a large data gap from December 1997 to April 1998, which does not allow any data comparison during this period. The rapid spring deceleration of the coastal current observed in the current meter data after May is located south of the $1000-\mathrm{m}$ isobaths in the altimetric current field, which also exhibits a clear minimum in August at the same place. This indicates a southward migration of the LPC current during the year 1998. In spring 1998, an anticyclonic eddy was reported by Pinot et al. (2002) to be trapped at the western flank of the LPC Current, just south of track 248. The presence of this mesoscale structure could explain the offshore deflection of the main current axis. In November/December
1998, both data sets exhibit important discrepancies. If a short southward winter acceleration of the flow was monitored by the current meter data, the current field derived from altimetry remains very low. This is explained by the presence of an intense anticyclonic eddy at the center of the Balearic Sea from September 1998 to March 1999 (Pascual et al., 2002). The presence of this structure has been shown to produce significant changes in the general circulation of the basin, diverting the shelf break current and even reversing the usual cyclonic circulation. Indeed, anomalous northeastward velocities are observed in the current meter record in February-March 1999, a reversal of the southwestward coastal current during the rest of the time series. This event is also clearly observed in the altimetric data in Fig. $4 \mathrm{~b}$, with a strong minimum located over the shelf break, moving offshore in April.

The rms values of, respectively, the filtered ADCP velocity at $100-\mathrm{m}$ depth and the surface altimetric ASGV are $6.8 \mathrm{~cm} \mathrm{~s}^{-1}$ and $8.4 \mathrm{~cm} \mathrm{~s}^{-1}$. The origin of this rms difference may be linked to a significant vertical shear between the surface geostrophic velocities (derived from the altimeter) and deeper velocities (ADCP data). The correlation values between the filtered velocities measured at $\mathrm{C} 1$ and the ASGV time series located above the continental shelf break vary between 0.55 and 0.62 . They are significant at the $99 \%$ level for 26 degrees of freedom (given the low-pass filter applied to the $\sim 24$ months record). Keeping in mind the along-track resolution of the altimetric currents $(\sim 20 \mathrm{~km})$, the fact that they only include the anomalous geostrophic component perpendicular to the track, that the measurements are not made at the same place and that the current meter is located at $100-\mathrm{m}$ depth, this comparison of the altimetry-derived cross-track current 
anomalies with in-situ observations shows reasonably good qualitative agreement in the seasonality of the shelf edge current.

Marked interannual differences are observed in both current meter and altimetric-derived current records during the period analyzed. They can be, at least partly, related to a strong year to year modulation in the eddy activity in the area (Pinot et al., 2002). A smoother pattern obtained from a climatological analysis of altimetric-derived current variations will be discussed in Section 4.

\subsection{Comparison in the Ligurian Sea}

In this section, the monthly climatology of the LPC amplitude derived from ship ADCP observations collected during DFM transects (see location in Fig. 2) is compared with the climatology computed from altimetric data along track 222. A mean synthetic geostrophic current profile has been added to the altimetric ASGV, derived from the regional Rio Mean Dynamic Topography along track 222 (Rio et al., 2007). North of $\sim 42.9^{\circ} \mathrm{N}$, the mean geostrophic currents exhibit positive values increasing to $10 \mathrm{~cm} / \mathrm{s}$ at the northern tip, consistent with the presence of the westward-flowing LPC current (not shown). According to previous work, this value may be underestimated, due to a too coarse resolution of the MDT product $\left(1 / 8^{\circ}\right)$ compared to the spatial scale of the circulation features of interest. However, this simple data analysis gives some confidence to use the retrieved mean current information. Since the vein of the current meanders and given that we have observations which differ in space and time, we have chosen to detect the maximum positive anomaly for each DFM transect and each altimeter cycle. Concerning along-track data, the selection was restricted to a distance spanning $80 \mathrm{~km}$ to the coast and only data from January 2000 to October 2007 were used. The information collected is then synthesized in a monthly climatology of the altimetric-derived LPC amplitude anomaly. Only variations around the respective mean annual value will be discussed. Due to the narrowness of the shelf and the steepness of the slope in this area, the number of altimetric data along track 222 collapses at the base of the continental slope, where we expect to observe the main flow of the LPC current (see also Fig. 7b). Moreover, we have to keep in mind that the altimetric-derived currents have an along-track resolution of $\sim 20 \mathrm{~km}$, which is lower than the first internal Rossby radius ( 7 to $11 \mathrm{~km}$ over the area of interest; Grilli and Pinardi, 1998) and only include the geostrophic velocity component normal to the track. Therefore, we expect the altimetric current variations to be underestimated. This is a limitation of this comparison exercise with a section of in-situ observations which, by contrast, has a resolution of $2 \mathrm{~km}$ and reaches the $200-\mathrm{m}$ isobath, thus providing information on the velocity field over the continental slope.

According to previous studies, off Nice, the LPC is expected to be faster, narrower and closer to the coast in winter and autumn, and to slow down, become wider and move offshore in summer (Millot, 1991; André et al., 2005). It is also subject to mesoscale activity, especially during winter, with the formation of meanders on its edge (Millot, 1991; Flexas et al., 2004). Given the heterogeneous temporal distribution of selected DFM transects, the climatology of the LPC amplitude measured with ADCP might then be affected by the presence of mesoscale features.

Fig. 5 shows the seasonal variability of the LPC amplitude (bold line) as calculated from the ADCP data DFM line (top) and from satellite track 222 (bottom). The standard deviations around the monthly mean values are also indicated (thin line). Both LPC amplitude climatologies exhibit a similar seasonal cycle, with maximum values in winter and minimum values in summer. This result agrees well with previous studies mentioned above, i.e. a strengthening of the LPC current in winter and a weakening in summer. As expected, due to the difference of spatial sampling between the two data sources, the peak to peak amplitude variation is much smaller (by a factor of 2 ) in Fig. $5 \mathrm{~b}(\sim 12 \mathrm{~cm} / \mathrm{s}$ ) than in Fig. $5 \mathrm{a}(\sim 25 \mathrm{~cm} / \mathrm{s})$. The standard deviations around each average value indicate a greater variability during the winter months and a minimum variability in summer but it remains significant throughout the year, showing important year-to-year modulations of the seasonal cycle. This increase in variability is better observed in the ADCP data, but it could be partly due to the number of samples used to compute the LPC amplitude climatology which is much lower and heterogeneously distributed in time. The estimates of the ADCP current anomalies are positive from October to April, with a maximum in February and reach their lower values during summer months. From altimetry, the coastal current appears to strengthen from September to February, with a maximum in December and to be at its slowest during summer months. The most significant differences between the ADCP and altimetry-derived values are then observed during the first months of the year. Given that the LPC Current is expected to be narrower and closer to the coast in winter and that along track 222, altimetric data become unreliable just off the shelf break (while ADCP measurements reach the coastal edge of the continental slope), this could indicate the failure of altimetry to capture a significant part of the LPC Current during this period.

In conclusion, despite the relatively low spatial sampling of altimetry compared to the width of the LPC current and its intrinsic difficulties in this narrow-shelf area, the seasonal variations in amplitude noticed in $\mathrm{ADCP}$ data and already reported in the literature are clearly observed: a faster (slower) LPC current in winter (summer). The ADCP LPC amplitude values show a more energetic seasonal signal than the altimetry-derived currents, which can largely be explained by the difference in spatial/ temporal resolution.

At this stage, we have seen that, on seasonal time scales, the geostrophic current variations derived from altimetry are consistent with those observed in independent current observations. This leads us to the conclusion that the satellite ASGV data can be used to

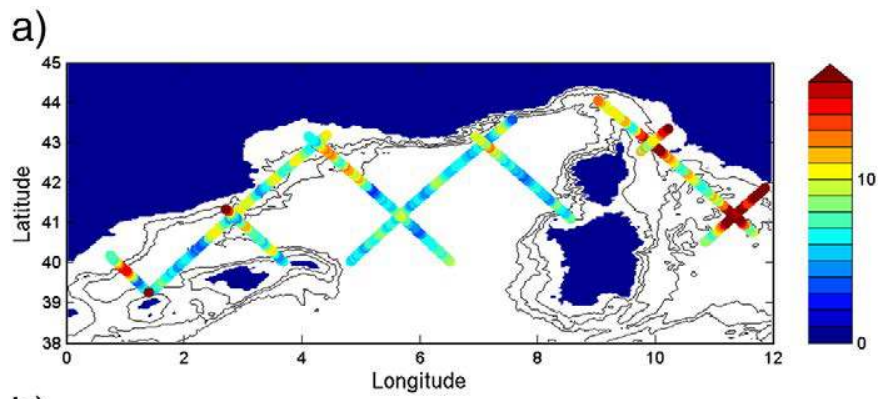

b)

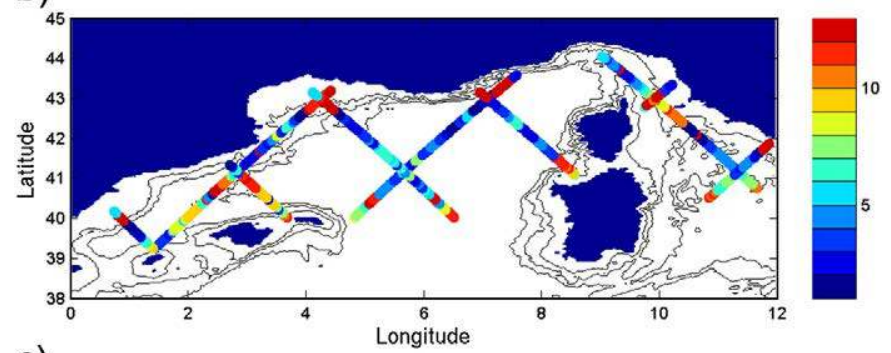

c)

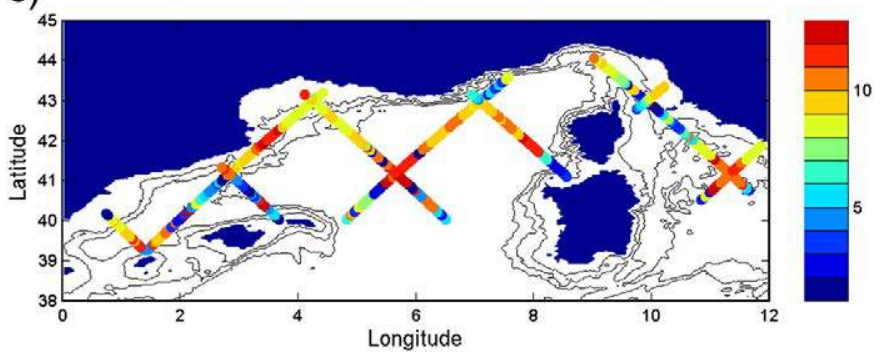

Fig. 6. a) Maximum amplitude (in $\mathrm{cm} / \mathrm{s}$ ) observed in the seasonal cycle of the surface current field deduced from altimetry. This value is the difference between the maximum and minimum values observed. Time, given in month number, during which the maximum (b) and minimum (c) values are observed. 
analyze the seasonal evolution of the LPC system on a regional basis. Note that these comparisons would be impossible with standard altimetric products given the small number of available observations in the shelf break region for tracks 222 and 248 (Fig. 3).

In the remainder of this study, we use the surface current anomaly climatology to examine the seasonal variability of the highly fluctuating coastal circulation estimated from satellite altimetry in the region of interest (Figs. 6 and 7). SST imagery is used to further analyze the major features highlighted by the ASGV climatology as well as to provide supplementary information on the LPC coastal current system (Figs. 8 and 9).

\section{Regional analysis of the seasonal evolution of the circulation near the shelf break}

\subsection{General characteristics of the seasonal variability from altimeter data}

To analyze the seasonal variations of the circulation in the area of interest, we have extracted temporal and intensity characteristics from the ASGV climatology. This has been done by computing, for each altimetric data point, the months during which the maximum and minimum values are observed in the climatological ASGV time series, as well as the absolute difference, $A$, between the extrema. The results are shown in Fig. 6. The 200-m, 1000-m and 2000-m isobaths are superimposed. Note first the very good internal consistency of the results, which can also be considered as validation of the altimetricderived currents. In Fig. 6a, larger values of absolute amplitude, $A$, (10$15 \mathrm{~cm} / \mathrm{s}$ ) are systematically observed on the shelf break, associated with abrupt cross-shore gradients. It coincides with the expected location of the LPC current system which behaves as a coastal boundary jet (Echevin et al., 2003). The maximum values of $A$ are obtained in the northern Tyrrhenian basin and in the southern Ligurian Sea $(>16 \mathrm{~cm} / \mathrm{s})$, and will be discussed in Section 4.3. The combination of the amplitude and temporal characteristics of the seasonal variations observed gives a nearly in phase velocity anomaly along the shelf slope of the Northwestern Mediterranean Sea, from the Northern Tyrrhenian Sea to the Balearic Sea. The maximum amplitude of the coastal current anomaly (Fig. 6b) is reached in December for the Tyrrhenian, Ligurian and Provençal basins, and moreover, in January along the Catalan shelf a)

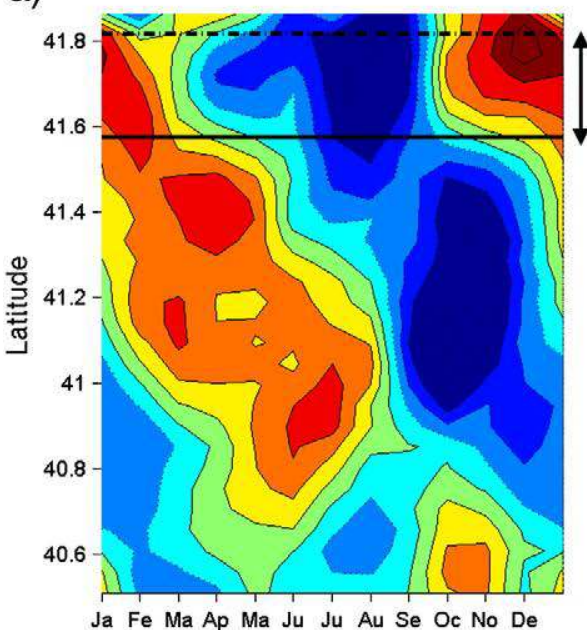

c)

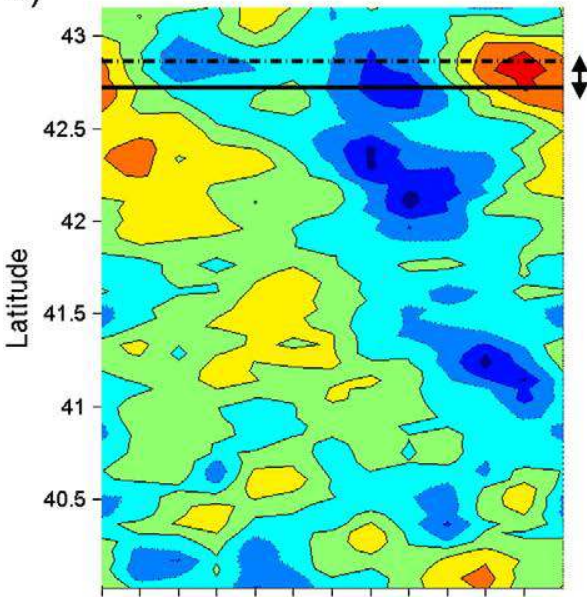

Ja Fe Ma Ap Ma Ju Ju Au Se Oc No De b)

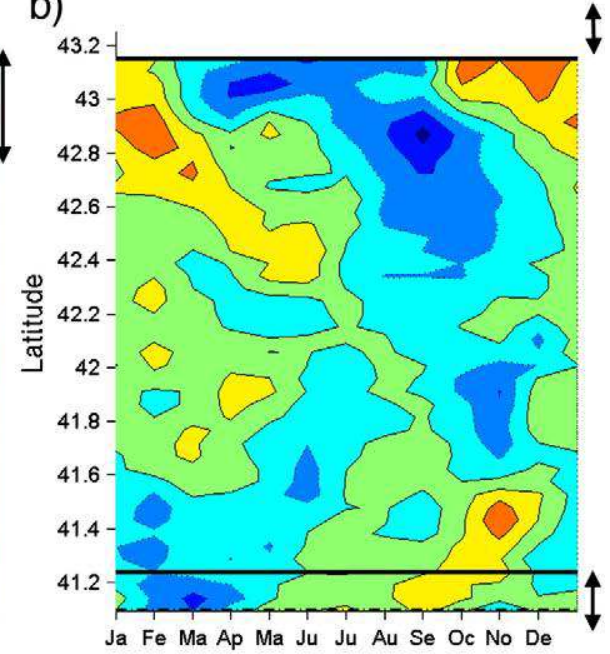

d)

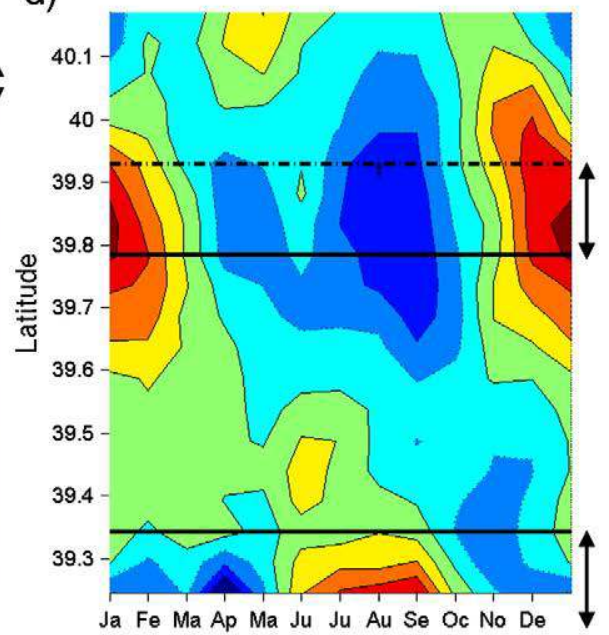

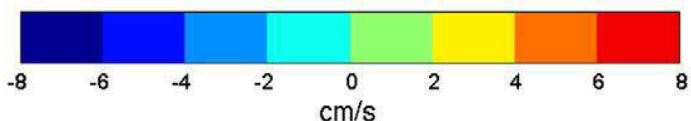

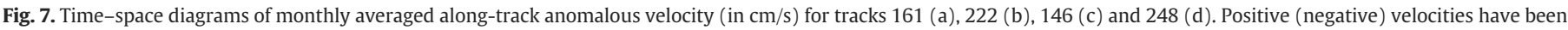

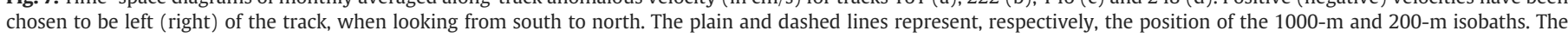
contour interval is $2 \mathrm{~cm} / \mathrm{s}$. Black arrows indicate the location of the continental shelf break. 
a)

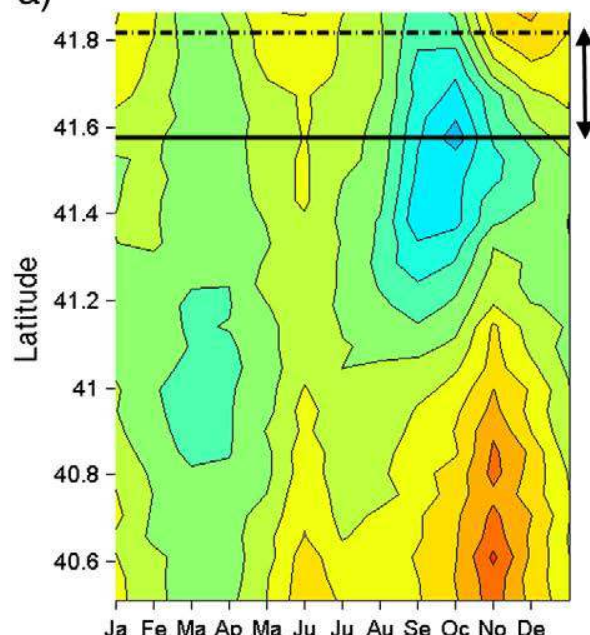

c)

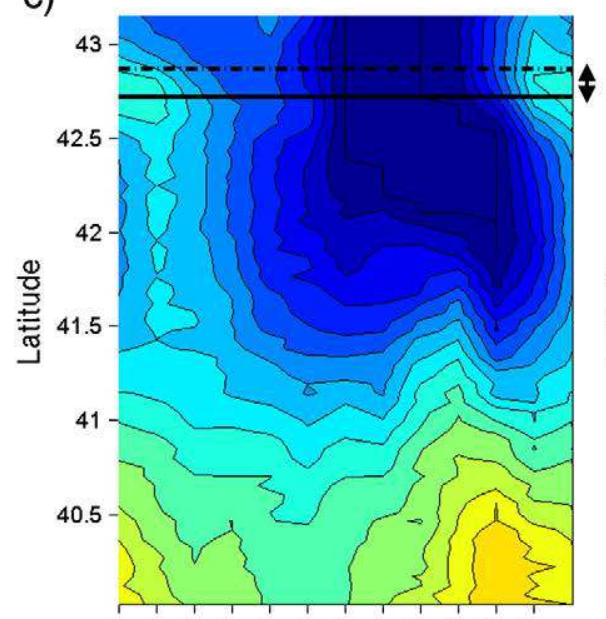

Ja Fe Ma Ap Ma Ju Ju Au Se Oc No De b)

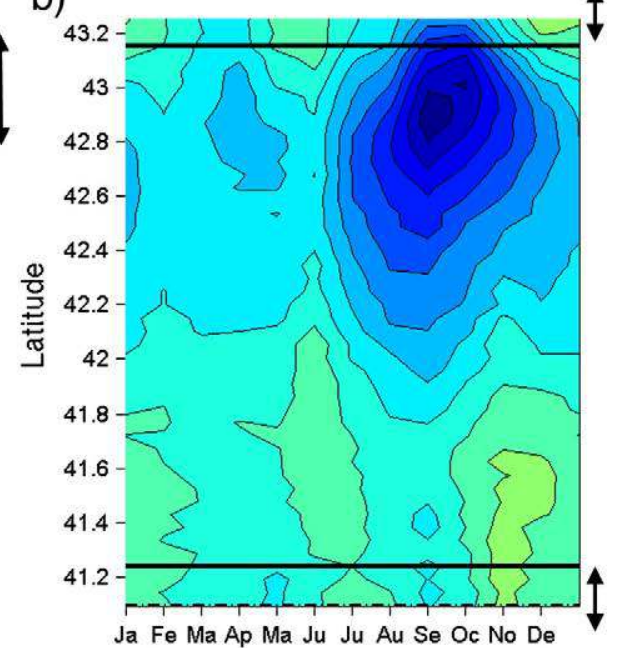

d)

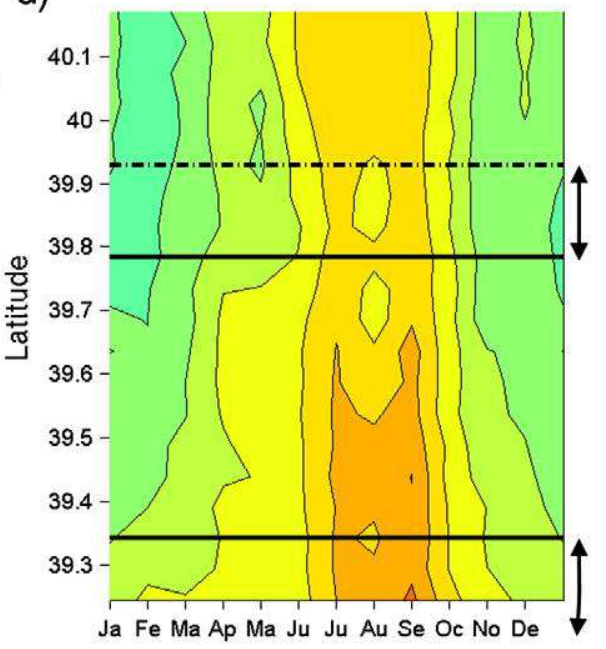

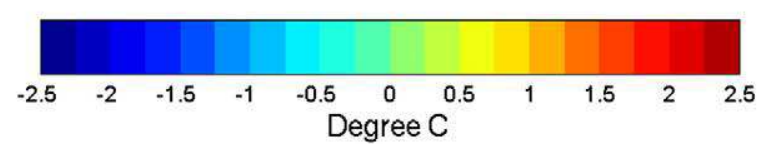

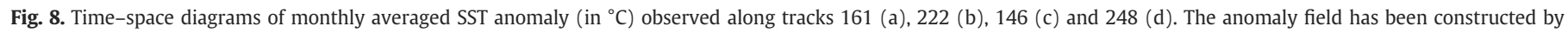

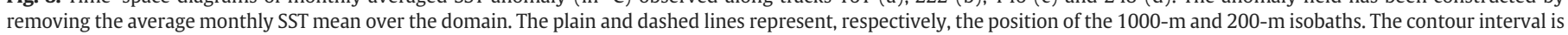
$0.25{ }^{\circ} \mathrm{C}$. Black arrows indicate the location of the continental shelf break.

(note that the monthly resolution of the climatology does not allow us to detect if this shift corresponds to propagation). The corresponding minimum (Fig. 6c) generally appears around August but also displays larger dispersion over the region (ranging from May to October) than the phase of the maximum. We can observe this more clearly in Fig. 7, representing a more detailed time-space diagram of the ASGV climatology for selected tracks (tracks 161 (a), 222 (b), 146 (c) and 248). For each of these tracks, near the shelf break (200-m isobath), we can see that in late autumn the current amplitude suddenly increases and then rapidly decreases at the end of the winter season: the transition to winter condition is very abrupt. The period of maximum is thus very short and well marked in the ASGV climatology. However, the negative phase spreads over a much larger period with a less clearly defined minimum. The same thing is observed for all tracks along the shelf (not shown).

Fig. 6 suggests that a strong link exists between the seasonal oscillation of the LPC Current and the seasonal change of the flow along the western coast of Italy. On the other side of Sardinia and Corsica islands (along the west coast), the seasonal variability observed near the continental shelf appears much less pronounced $(6-8 \mathrm{~cm} / \mathrm{s}$ on track 222 ) than in the northern Tyrrhenian basin (see also the southern part of Fig. 7b). If we assume a northward coastal current along the north western Sardinia (Astraldi and Gasparini, 1992; Astraldi et al., 1994), the lowest velocity anomalies are observed in October-November and the maximum current amplitude is reached between January and March (according to the convention we have chosen, i.e. current anomalies positive to the left of the track). Therefore, a 1-2 month time lag is observed with respect to the maximum of the LPC Current. In agreement with previous work (Astraldi et al., 1990, 1994), it seems to indicate that the sudden winter increase of the LPC Current cannot be related to an intensification of the WCC (flowing along the West Sardinian and Corsican coasts). Nevertheless, one must keep in mind that the WCC is being poorly sampled by T/P and Jason-1 altimeter data. It is therefore difficult to draw any definitive conclusions on the WCC variability in the absence of additional information.

Significant seasonal variations of geostrophic velocities are also observed in the centre of the Ligurian-Provençal Basin $(10-12 \mathrm{~cm} / \mathrm{s}$ ) on tracks 222 and 146 with a maximum (same convention as the 


\section{a)}

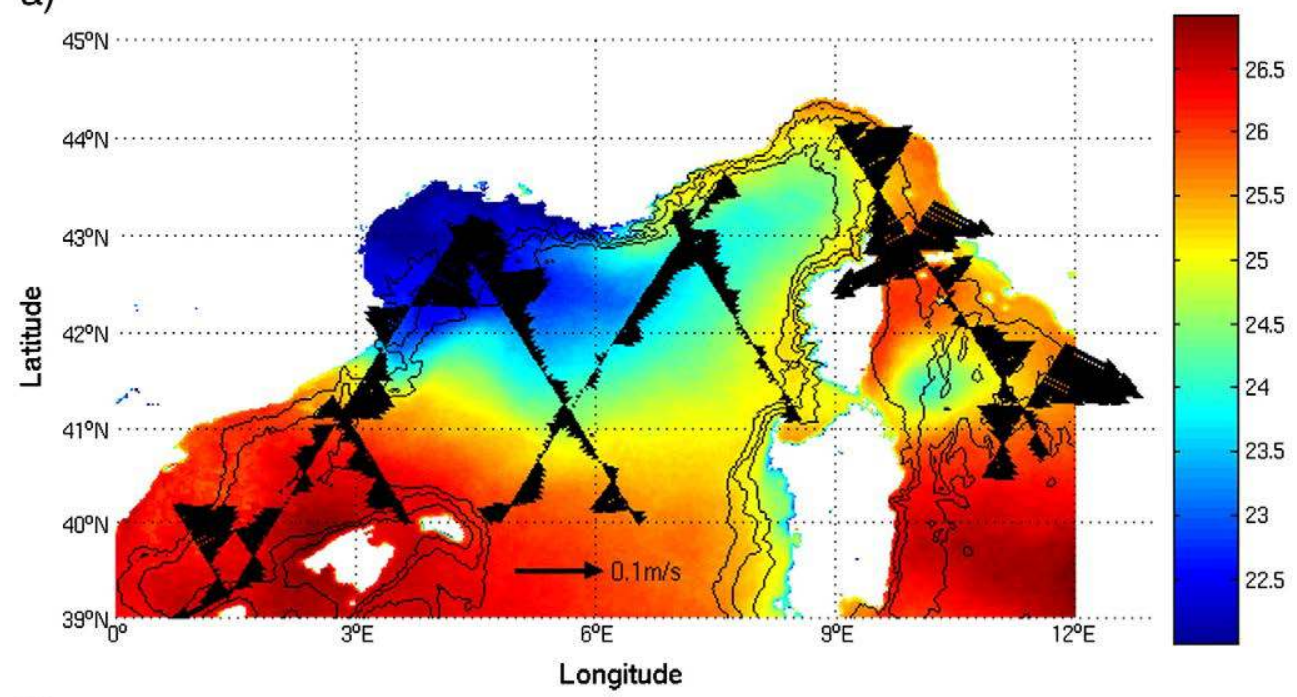

b)

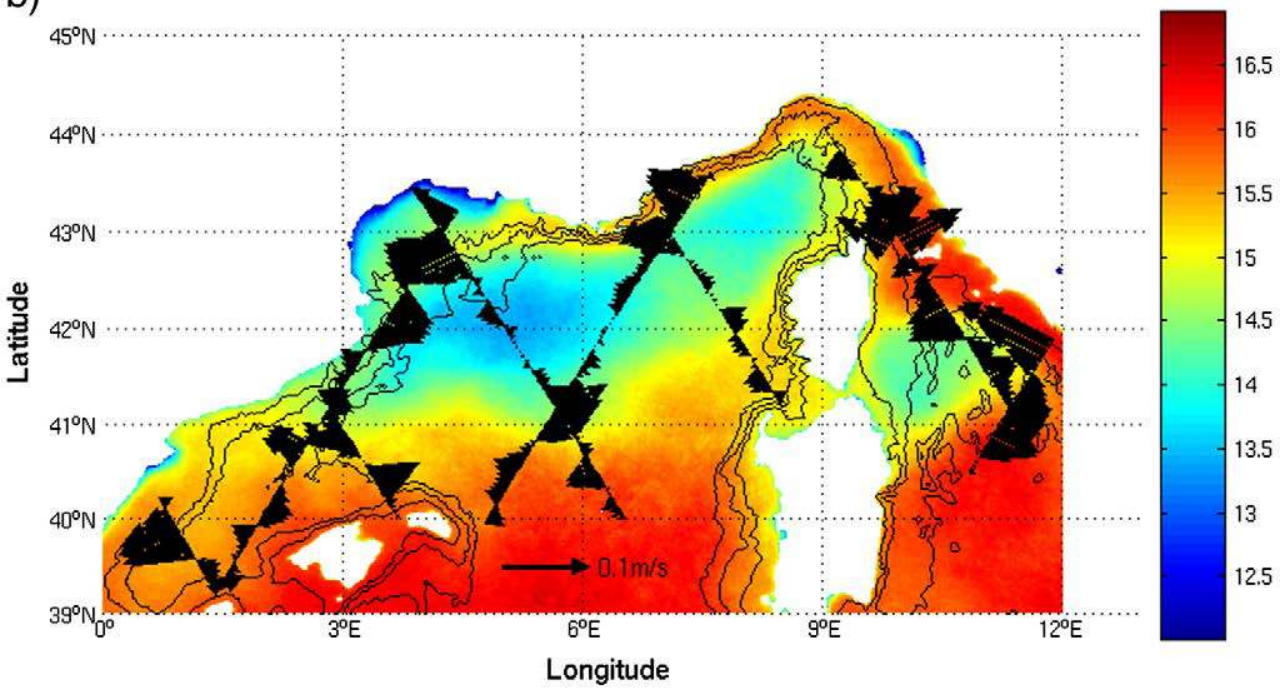

Fig. 9. Monthly climatology maps of cross-track geostrophic current anomalies (derived from altimeter data) and of SST for August (a) and December (b).

coastal current) around January and a minimum in September (see also Fig. $7 \mathrm{~b}$ around $42.9^{\circ} \mathrm{N}$ and Fig. 7c around $42.2-42.3$ ). The seasonality of these currents seems to be shifted by about one month compared to the coastal current. Up to now, these circulation features have not been documented. A more specific analysis of the data could help to understand whether they could correspond to a continuous branch of current and/or if these anomalies progressively shift southward as suggested by Fig. 7b and c.

The multi-year ASGV records indicate that the seasonal variability reported here is a robust feature everywhere near the shelf break. A spectral analysis has also shown that the seasonal cycle dominates the variability at all locations along the LPC system (not shown), which confirms previous studies. Moreover there are important year to year modulations of the annual variability, in both amplitude and phase. The timing of the current increase or decrease can vary by about 2 months from one year to another. It results in a smoothing of the seasonal variability observed from the ASGV climatology which is computed from $\sim 14$ years of data.

\subsection{Comparison with sea surface temperature}

Since the LPC Current is known to be associated with a shelf slope density front (Astraldi et al., 1994; Rubio et al., 2005), the seasonal variations of its flow are expected to have a thermal signature in SST data. To improve the visibility of the boundary circulation from the dominant basin-wide seasonal heating cycle, SST anomalies were constructed by removing the domain-average monthly SST value from the monthly SST climatology. Latitude-time diagrams of monthly SST anomalies are extracted along the same selected altimeter tracks as in Fig. 7, and presented in Fig. 8. During spring and summer, the SST anomalies appear relatively homogeneous for all the diagrams: no clear thermal separation is observed between shelf and open-sea waters across the continental shelf. In late autumn, the spatial pattern of SST anomalies clearly changes and the temperature structure of the shelf edge region starts to stand out from the surrounding waters. In November-December, a significant meridional SST gradient rapidly develops along the shelf edge. The surface waters over the shelf break are warmer than the surrounding waters along tracks 161, 222 and 146 (from the Tyrrhenian Sea to the Gulf of Lyon) and slightly colder along track 248 (in the Balearic Sea), where the gradient of SST remain very weak (Fig. 8d). This thermal front then rapidly disappears in February. In Fig. 8, the contrast between waters carried by the coastal circulation and shelf or open-sea waters is then only clearly visible during winter (see also Fig. 9). It confirms that (André et al., 2005) the coastal circulation is readily apparent in satellite SST maps during winter, in the presence of a homogeneous upper layer (the density 
front associated with the boundary flow then reaches the surface water). Whereas in summer, it seems to be masked by the large-scale seasonal thermocline. Note that this is not always true when looking at individual SST maps: the SST climatology only reflects an average situation.

However, the most striking aspect of Fig. 8 is that, along the different tracks, the winter transformation of the spatial pattern of SST anomaly close to the shelf edge remarkably corresponds to the winter intensification of the boundary flow observed in Fig. 7. This is also obvious in other representations of the SST and ASGV climatologies. Fig. 9 shows the horizontal field of the monthly SST climatology for August (Fig. 9a) and December (Fig. 9b), overlain by the cross-track velocity anomalies (from the ASGV climatology) for the corresponding month. These two months correspond to the times during which the maximum and minimum current amplitude have been observed in altimeter data along the continental slope. From the Tyrrhenian Sea to the Gulf of Lyon, the winter SST pattern in Fig. 9b shows a steep thermal front over the shelf break that separates the relatively warm waters of the coastal flow from the colder open-sea waters. As already observed in Fig. 8, the surface thermal field of the Balearic Sea is relatively uniform and the boundary flow cannot be clearly identified in this region. By contrast, in summer, the cross-shelf SST gradient is much weaker and even disappears in the Gulf of Lyon. The latter feature could indicate that, at that time, due to strong wind conditions and the weakening of the LPC Current, the latter is maintained in subsurface in this area, while colder upwelled surface waters spread southward from the Gulf of Lyon. The southward motion of surface drifter trajectories in this area during summer time has also been reported in Poulain (2008).

When comparing the spatial structure of the cross-track velocity anomalies and the spatial structure in the SST fields, a very comprehensive picture of the seasonal evolution of the current system appears: intensification (decrease) of the boundary flow in winter (summer). The transformation from the summer to the winter flow regimes is clearly observed on Fig. 9. This comparison also provides supplementary information on the circulation system. For example, the Balearic Front, identified by an important thermal front from the Balearic Sea to the Ligurian Sea, is obvious in the SST patterns: it corresponds to the eastward return branch of the LPC Current. Offshore from the Gulf of Lyon, this front is located at approximately $41^{\circ} \mathrm{N}$. The Balearic Front, whose position undergoes significant changes from winter to summer is not easily detected in velocity anomaly fields alone (see Fig. 7b and c). By contrast, the December (August) picture of SST and altimeter velocities shown in Fig. 9b depicts a winter intensification (southward shift) of this branch of the circulation.

This analysis highlights the strength of the altimetric data in observing the coastal circulation in all seasons (except when the current moves to less than $\sim 20 \mathrm{~km}$ from the coast). Altimetry continues to monitor the geostrophic current even in summer, while the SST observations then measure the surface mixed layer properties. However, in winter, the surface coastal circulation of the Northwestern Mediterranean Sea can be observed by both altimetry and SST imagery. In the following, we examine some local characteristics of the surface current variability in two sub-basins, the Tyrrhenian Sea and the Balearic Sea.

\subsection{The Tyrrhenian Sea}

As mentioned above, the highest intensity of the seasonal cycle appears in the eastern part of the domain, i.e. in the northern Tyrrhenian Sea (track 161) and in the southern Ligurian Sea (tracks 44 and 85), with values greater than $16 \mathrm{~cm} / \mathrm{s}$. Important seasonal variations of the circulation have already been reported in this area (Astraldi et al., 1990; Astraldi and Gasparini, 1994). Surprisingly, in the Corsica channel (between Corsica and Capraia), where important variability of the flow is also expected (Astraldi and Gasparini, 1992; Vignudelli et al., 2005), the observed variability appears to be relatively low (see Fig. 6). This is largely explained by the poor quality of altimetric data in this particular area; indeed, most of them have been eliminated during the processing. On the Italian shelf (between the $200 \mathrm{~m}$ isobaths and the coast), along track 85 , the seasonal maxima are observed in January, and the minima appear in September (Fig. 6), slightly later than those generally observed along the continental slope of the Northwestern Mediterranean Sea. However, from the analysis of the results along tracks 44 and 85 (Figs. 6 and 9), a clear picture of the surface circulation variability emerges in this area: intensification (decrease) of the northward current in winter (summer).

In the northern Tyrrhenian Sea, along tracks 161 and 44, the amplitude of the seasonal cycle is particularly pronounced (Figs. 6 and 7). Between the coast and the $1000 \mathrm{~m}$ isobath, the maximum (minimum) of the northward current anomaly is observed in December (August). This is consistent with the LPC system. In the northern Tyrrhenian Sea, the circulation is characterised by an important seasonal modulation which has been documented in previous studies (for example: Artale et al., 1994; Astraldi and Gasparini, 1994; Marullo et al., 1995). Most of these investigations are based on hydrographic and current meter measurements. The circulation north of $40^{\circ} \mathrm{N}$ is influenced by the presence of the semi-permanent Bonifacio Gyre, produced by the wind jet blowing from the Strait of Bonifacio (Astraldi and Gasparini, 1994). This cyclonic gyre, previously observed by open-ocean altimetric observations (Pujol and Larnicol, 2005) and SST imagery, extends from one coast to the other in summer and spans the western part of the basin in winter (Artale et al., 1994). During the winter-spring period, the circulation has been observed to be much more energetic, with a northward coastal current flowing along the Italian coast (the Tyrrhenian Current), from the Sardinian Channel to the Corsican Channel, then linking the Tyrrhenian Sea to the rest of the Ligurian-Provençal Basin via the Corsica Channel. In summer and autumn, this link vanishes: the northward coastal current decreases or disappears (Marullo et al., 1995). The circulation then appears more complex and fragmentary, mainly characterised by smallscale eddies and gyres in the centre of the basin.

The variations observed in the monthly cross-track ASGV climatology computed from tracks 161 and 44 (Figs. 7a and 9) are consistent with the circulation changes mentioned above. Along track 161 , the strongest variations in the current field are observed on the continental slope, near the $200-\mathrm{m}$ isobath (around $41.8^{\circ} \mathrm{N}$ ), with peak to peak amplitudes higher than $16 \mathrm{~cm} / \mathrm{s}$ (Fig. 7a). As already mentioned, the northward surface current anomaly is maximum in December and minimum in August. The current strengthens very quickly and over a short time period (2-3 months). From both Figs. 6 and $7 \mathrm{a}$, the positive anomaly shifts offshore over time, reaching a maximum in February around $41.6^{\circ} \mathrm{N}$. This could correspond either to a southward migration of the coastal current axis, or to a broadening of the current jet. Offshore, the surface current variability remains very high. The lowest current anomalies ( $\sim 8 \mathrm{~cm} / \mathrm{s}$ to the southeast) are observed in October near $41.1^{\circ} \mathrm{N}$ and the highest anomalies $\left(\sim 6 \mathrm{~cm} / \mathrm{s}\right.$ to the northwest) are found around $41.4^{\circ} \mathrm{N}$ in March/April (Fig. 7a). Since we are dealing with anomalies, this apparent reversal of the currents from one season to another could also represent a weakening of the offshore cyclonic circulation at the end of summer. From Fig. 9, this change of the surface circulation in the centre of the Tyrrhenian basin seems to be strongly related to the seasonal change of the Bonifacio Gyre characteristics.

\subsection{The Balearic Sea}

A particular region of interest is the Balearic Sea because the continuity between the Liguro-Provençal Current and the Catalan Current is one of the questions still in debate in the scientific community. For example, Font et al. (1988) and Millot (1991) observed a year-round continuity, when 
Herbaut et al. (1997) suggested that this relationship only exists in summer. Moreover, most of the studies in the Balearic Basin have been carried out during the spring-summer period (Castellón et al., 1990; García et al., 1994; Pinot et al., 1995). As a result, they do not reveal the different aspects of the seasonal variability of the circulation.

The surface circulation in the Balearic Sea is dominated by two well defined density driven currents. In the northern part, a frontal jet flows southwestward along the slope (Castellón et al., 1990). In the south, off the Gulf of Valencia, part of the flow continues its path southward along the Spanish coast. Another branch bifurcates and recirculates cyclonically to feed the return Balearic Current along the northern Balearic Islands shelf. The latter is also fed by a northward flow coming from the south through the Balearic Channels (Pinot et al., 2002).

Fig. 7d shows the time-space diagram of the monthly cross-track ASGV climatology computed along track 248 that crosses the southern part of the Balearic Sea. Once again, the strongest seasonal modulations of the surface flow are observed on both the southern and northern continental slopes. In the northern area, the maximum is found around $39.8^{\circ} \mathrm{N}$, with peak to peak amplitudes of $\sim 14 \mathrm{~cm} / \mathrm{s}$. In the southern area, the second maximum has the same amplitude and is located around $39.25^{\circ} \mathrm{N}$, just north of the $200-\mathrm{m}$ isobath. This result provides evidence of the two energetic coastal streams mentioned above: the south westward Catalan Current to the north and the north eastward (opposite in direction) Balearic Current to the south. Both are associated with important seasonal variations which appear in phase: both flows increase during winter and decrease during summer (note that positive anomalies are westward, whereas the Balearic Current flows to the northeast). However, some differences also appear. If the Catalan Current shows seasonal characteristics nearly in phase and very close to those already observed along the LPC Current path (i.e. a sudden increase in autumn, followed by a short period of high strength in December/January, a rapid decrease in early spring and then a large period of lower intensity), the southern flow exhibits discrepancies from this behaviour. The winter regime lasts much longer (from October to May) and the maximum in intensity is observed in April. This suggests significant differences between the dynamic conditions that affect the alongslope circulation in the north and the south of the Balearic Sea, mostly during the spring. The Balearic channels are known to play an important role in the regional circulation of this area. According to Pinot et al. (2002), during the spring, when the intensity of the Catalan Current decreases, southern waters, previously blocked by the dominant southwestern current, flow northward through the channels. This advection may reinforce the Balearic Current and explain the maximum observed around April.

Finally note that, as illustrated in Fig. 4b, the seasonal variations of the coastal circulation system displayed in Fig. 7d can be significantly perturbed in individual years. The shorter period variability observed in Fig. 4b, and mainly associated to the movement of jet meanders and eddies, is filtered out by the time averaging process. It also emphasizes the seasonal cycle of the LPC Current, showing that it is a persistent component of the regional ocean circulation throughout the altimeter data record.

\section{Discussion and conclusion}

To our knowledge, this is the first time that the variability of the LPC boundary current system, which is narrow in width $(20-30 \mathrm{~km})$, is analyzed on a regional basis using along track altimeter data. This kind of exercise has been performed for other narrow boundary currents, such as the Leeuwin Current (Deng et al., 2008), but is strongly limited by the error level and the reduced availability of classical altimeter data near coastlines. In our case, the use of a coastal dedicated data processing provides much more reliable estimates of sea level anomalies (SLA) 25$30 \mathrm{~km}$ from the coast, and also significantly more near-shore information. The signature of the boundary current system clearly appears in the resulting along track data. The comparisons with in-situ current and satellite SST fields have shown that cross-track altimeter-derived current data, despite their coarse spatial resolution $(\sim 20 \mathrm{~km}$ in the along-track direction) are able to reasonably well capture the seasonal evolution of the LPC coastal current at different locations along its path. This indicates that satellite altimetry can be combined with other observations in order to depict the LPC Current characteristics.

The 14-year time series of ASGV data derived from TOPEX/Poseidon and Jason-1 satellites have been used to compute a monthly climatology of the surface current variations. Due to this long time series of observations, it is possible to separate the seasonal component of the variability from the mesoscale and interannual ones. The synoptic character of satellite data allows us to treat the boundary current of the Northwestern Mediterranean Sea as a coherent structure and hence document the seasonal evolution of the shelf edge circulation over the whole system. This basin-scale monitoring is not possible with in-situ observations nor SST data which cannot adequately observe the coastal currents in summer.

Despite its limited spatial resolution, the results for the seasonal picture of the coastal circulation system that emerges from altimetry agree fairly well with the somewhat piecemeal one deduced from historical observations (hydrography and in-situ currents) in the northwestern Mediterranean Sea (Astraldi et al., 1990; Millot, 1991; Albérola et al., 1995; Pinot et al., 2002). The main coastal features observed in the different sub-basins all show a strong seasonal signal with weaker (stronger) intensity in summer (winter). The timing of the seasonal signal appears very similar in the different sub-basins, especially during winter time. Over the studied period, on average, the shelf circulation increases during autumn to reach the strongest intensities in December/January. This period of maximum corresponds to that reported by Albérola et al. (1995) and Béthoux et al. (1982) from hydrological surveys. The intensification is quite sudden everywhere. This spatial homogeneity, as well as the spatial structure in the SST fields, suggests the existence of a unique stream along the entire northwestern Mediterranean shelf break during winter time. The relationship with the Balearic Current which is observed to be the strongest in spring appears somewhat more complex and suggests that its evolution is controlled by another inflow contribution, at least in spring. The evolution of coastal current velocities observed during the weaker summer regime (lasting longer, from March to October, except for the Balearic Current) appears much smoother. The minimum values are generally observed in August but significant dispersion is observed from place to place, suggesting a more complex circulation than during winter time. This difference between the characteristics of the summer and winter flow regimes leads to the following question: the smooth seasonal pattern described above is the average pattern of the shelf circulation, but is this pattern more highly fluctuating in spring/summer than in autumn/winter, due to higher year-to-year modulation and/or local hydrodynamic influence? In order to analyze this hypothesis, we have computed for different tracks $(161,146$ and 248$)$ the averaged seasonal climatology of the ASGV data over the continental slope and the monthly standard deviations (Fig. 10). The standard deviations are lower for track 146 (along the shelf break of the Gulf of Lyon; Fig. 10b) than for track 248 (in the northern Balearic Sea; Fig. 10c) and 161 (in the eastern Tyrrhenian Sea; Fig. 10a), but the amplitude of the corresponding seasonal variations is also lower. For each track, the standard deviations marginally vary but we do not systematically observe higher values during a particular season. Along the LPC current, the associated mesoscale variability is known to be particularly intense in spring and might account for the slight increase of the standard deviation values during this season.

In spite of the seasonal cycle discussed in this paper dominating the spectrum of the coastal circulation variability in the area of interest (not shown), it can be modulated over time. As illustrated in Fig. 10, the data reveal that important year to year differences exist in the seasonal cycle (in both phase and amplitude). The length of the altimetric time series is sufficient to begin studying low frequency current variations. Of particular 
a)

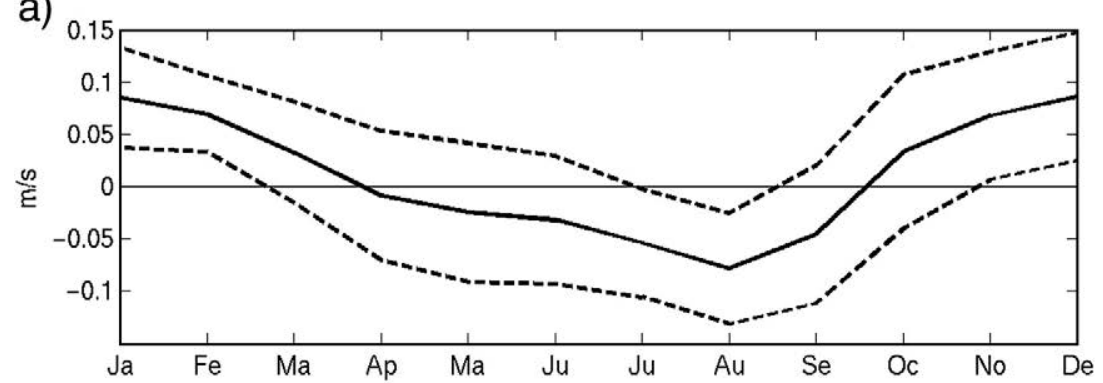

b)

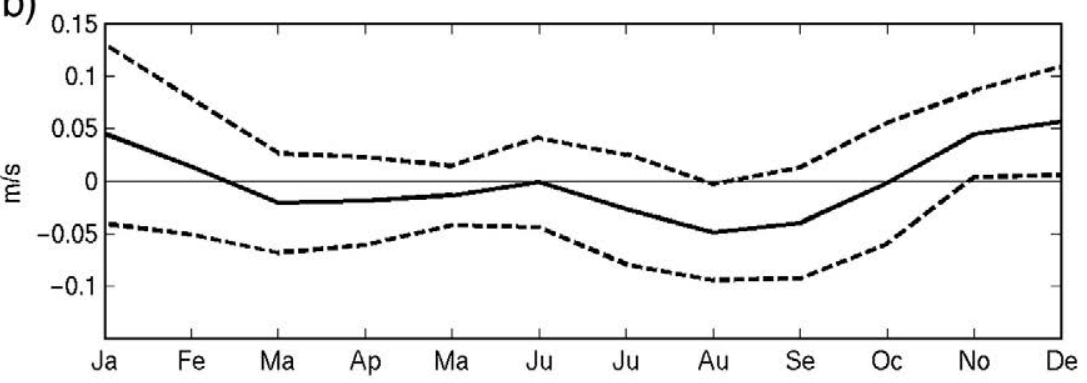

c)

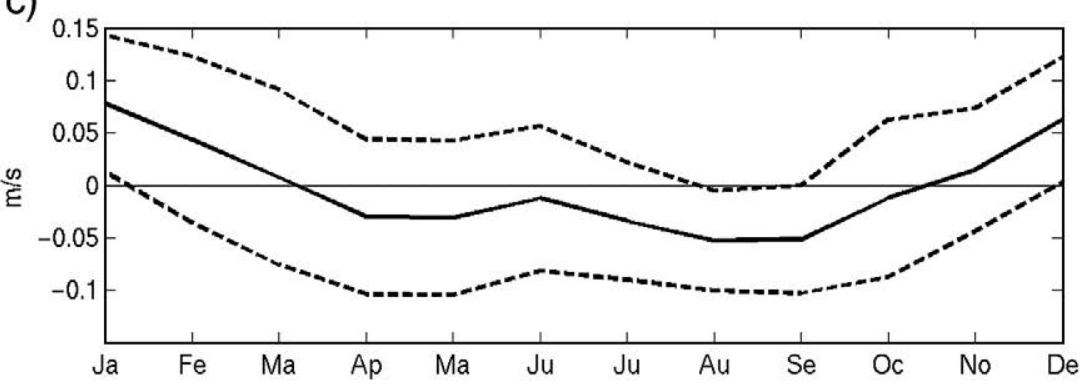

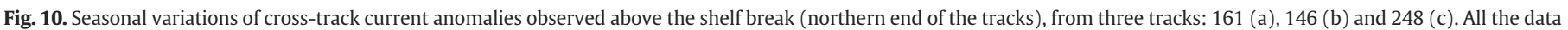
located between the $200-\mathrm{m}$ and the $1000-\mathrm{m}$ isobaths have been used. Monthly standard deviations are superimposed (dashed lines).

interest would be the documentation of the spatial structure of the interannual variability. How does it vary along the path of this shelf edge current system? Is it, like the seasonal component, regionally coherent? The analysis of the interannual component of the coastal circulation variability will form the subject of a future study. The Northwestern Mediterranean Sea is an area that is highly sensitive to atmospheric circulation in the North Atlantic (Send et al., 1999). In particular, according to previous studies (Vignudelli et al., 1999; Rixen et al., 2005), the North Atlantic Oscillation subsequently affects the Mediterranean circulation. The potential response of the LPC system in the different sub-basins will be further investigated.

In this paper, we have not analyzed all of the aspects of the seasonal variability of the circulation. In particular, the resolution of the whole shelf edge current system is strongly limited by the large inter-track spacing of the T/P and Jason- 1 missions. For example, the Western Corsica Current is poorly resolved. Further work is planned to extend this study using higher along-track sampling rate altimeter measurements $(10 / 20 \mathrm{~Hz}$ rather, i.e. $0.3 / 0.7 \mathrm{~km}$ spatial resolution, rather than usual $1 \mathrm{~Hz}$ ) as well as multisatellite data to increase the amount of available observations. Secondly, we do not have an accurate mean current component along the shelf edge, so we have only discussed the current anomalies. It is clearly evident that only the combination of different observing systems (in-situ data collection, HF radars, surface drifters, satellite remote sensing of surface properties) could resolve the full range of time and spatial scales of the evolution of the boundary flow. But this study demonstrates that geostrophic currents computed from altimeter data have the potential to detect a large part of the variability of the slope circulation in the Northwestern Mediterranean Sea. Therefore, we believe that satellite altimetry, even with its intrinsic limitations, is an important component of coastal observing systems. Beyond the case study presented here, the nearly global availability of altimetry data holds considerable promise for advancing our knowledge of the variability of coastal ocean circulation, typically in those numerous regions where the surface boundary circulation is supposed to be of great interest, but is difficult to observe with direct in-situ measurements.

The altimeter data set used in this study as well as other alongtrack SLA products reprocessed on a regional basis with the X-TRACK software are available through http://ctoh.legos.obs-mip.fr/products/ coastal-products/coastal-products.

\section{Acknowledgements}

This study was funded by the French Ministry of Research and the CNES. Support from these institutions is gratefully acknowledged. This work is also sponsored by the TOSCA CNES program. Altimetry data used in this study were developed, validated, and distributed by the CTOH/LEGOS, France (http://www.legos.obs-mip.fr/en/observations/ ctoh/). The standard altimeter products were produced and distributed by Aviso (http://www.aviso.oceanobs.com/), as part of the Ssalto ground processing segment. We wish to acknowledge the contribution of the center that makes the satellite images available : the DLR (German Space Center: http://eoweb.dlr.de ) The rotor based Aanderra RCM7 current meter data were kindly provided by the Laboratori d'Enginyeria Marítima - UPC-Barcelona and processed by Gabriel Jorda. Processed and validated ADCP current data were provided by the INSU-DT data service centre. Finally, we thank the 
anonymous reviewers and Dr. Rosemary Morrow for their reviews, which helped to improve the quality of our manuscript.

\section{References}

Albérola, C., Millot, C., Front, J., 1995. On the seasonal and mesoscale variabilities of the Northern Current during the PRIMO-0 experiment in the western Mediterranean Sea. Oceanologica Acta 18, 163-192.

André, G., Garreau, P., Garnier, V., Fraunié, P., 2005. Modelled variability of the sea surface circulation in the North-western Mediterranean Sea and in the Gulf of Lyons. Ocean Dynamics 55, 294-308.

Artale, V., Astraldi, M., Buffoni, G., Gasparini, G.P., 1994. Seasonal variability of gyrescale circulation in the Northern Tyrrhenian Sea. Journal of Geophysical Research 99, 14127-14137.

Astraldi, M., Gasparini, G.P., 1992. The seasonal characteristics of the circulation in the North Mediterranean basin and their relationship with the atmospheric climatic conditions. Journal of Geophysical Research 97 (C6), 9531-9540.

AVISO, 1996. AVISO user handbook, Merged TOPEX/Poseïdon products, Tech. Rep. AVINT-02-101-CN, Ed. 3.0, 198 pp.

Astraldi, M., Gasparini, G.P., 1994. The seasonal characteristics of the circulation in the Tyrrhenian Sea. In: La Violette, P.E. (Ed.), Seasonal and Interannual Variability of the Western Mediterranean Sea: Am. Geophys: Union, Coastal and estuarine studies, 46, pp. $115-134$

Astraldi, M., Gasparini, G.P., Manzella, G., Hopkins, T.S., 1990. Temporal variability of currents in the eastern Ligurian Sea. Journal of Geophysical Research 95 (C2). doi:10.1029/89JC00239.

Astraldi, M., Gasparini, G.P., Sparnocchia, S., 1994. The seasonal and interannual variability in the Ligurian-Provenqal Basin. In: La Violette, P.E. (Ed.), Am. Geophys. Union, Coastal and estuarine studies, 46, pp. 93-114.

Béranger, K., Mortier, L., Gasparini, G.-P., Gervasio, L., Astraldi, M., Crépon, M., 2004. The dynamics of the Sicily Strait: a comprehensive study from observations and models. Deep Sea Research II 51, 411-440.

Béthoux, J.-P., 1988. Le courant Ligure au large de Nice. Oceanologica Acta 59-67 $\mathrm{n}^{\circ}$ spécial.

Béthoux, J.P., Prieur, L., Nyffeler, F., 1982. The water circulation in the North-Western MediterraneanSea, its relations with wind and atmospheric pressure. In: Nihoul, J.C.J. (Ed.), Hydrodynamics of Semi-Enclosed Seas - Proceedings of the 13th International Liège Colloquium on Ocean Hydrodynamics. Elsevier Press, Oxford pp. 129-142.

Birol, F., Morrow, R.A., 2003. Separation of the semiannual Rossby waves from the southeastern Indian Ocean coast. Journal of Marine Research 61, 707-723.

Bouffard, J., Vignudelli, S., Herrmann, M., Lyard, F., Marsaleix, P., Ménard, Y., Cipollini, P., 2008a. Comparison of ocean dynamics with a regional circulation model and improved altimetry in the North-Western Mediterranean. Terr. Atmos. Ocean. Sci. 19, 117-133. doi:10.3319/TAO.2008.19.1-2.117(SA).

Bouffard, J., Vignudelli, S., Cipollini, P., Menard, Y., 2008b. Exploiting the potential of an improved multimission altimetric data set over the coastal ocean. Geophysical Research Letters 35, L10601. doi:10.1029/2008GL033488.

Bouffard J., Roblou, L., Birol, F., Pascual, A., Fenoglio, Cancet, M., Morrow, R., Ménard, Y. in press. Validation and application of improved coastal altimetry strategies over the North Western Mediterranean Sea. Coastal Altimetry. Chapter 11, Springer Verlag Book.

Carrère, L., Lyard, F., 2003. Modelling the barotropic response of the global ocean to atmospheric wind and pressure forcing - comparisons with observations. Geophysical Research Letters 30 (6), 1275. doi:10.1029/2002GL016473.

Saraceno, M., Strub, P.T., Kosro, P.M., 2008. Estimates of sea surface height and nearsurface alongshore coastal currents from combinations of altimeters and tide gauges. Journal of Geophysical Research 113, C11013. doi:10.1029/2008JC004756.

Castellón, A., Font, J., García, E., 1990. The Liguro-Provençal-Catalan current (Northwestern Mediterranean) observed by Doppler profiling in the Balearic Sea. Scientia Marina 54 (3), 269-276.

Cleveland, W.S., Devlin, S.J., 1988. Locally weighted regression: an approach to regression analysis by local fitting. JASA 83, 596-610.

Crépon, M., Wald, L., Monget, J.M., 1982. Low-frequency waves in the Ligurian Sea during December 1977. Journal of Geophysical Research 87 (C1), 595-600.

Demirov, E., Pinardi, N., 2002. The simulation of the Mediterranean Sea circulation from 1979 to 1993. Part I: the interannual variability. Journal of Marine Systems 33-34, 23-50.

Deng, X., Featherstone, W.E., 2006. A coastal retracking system for satellite radar altimeter waveforms: application to ERS-2 around Australia. Journal of Geophysical Research 111, C06012. doi:10.1029/2005JC003039.

Deng, X., Featherstone, W., Hwang, C., Berry, P.A.M., 2002. Estimation of contamination of ERS-2 and Poseidon satellite radar altimetry close to the coasts of Australia. Marine Geodesy 25, 249-271.

Deng, X., Hwang, C., Coleman, R., Featherstone, W.E., 2008. Seasonal and interannual variations of the Leeuwin Current off Western Australia from TOPEX/Poseidon Satellite Altimetry. Terrestrial, Atmospheric and Ocean Sciences 19 (1-2), 135-149 ISSN 1017-0839.

Durand, F., Shankar, D., Birol, F., Shenoi, S.S.C., 2008. An algorithm to estimate coastal currents from satellite altimetry: a case study for the East India Coastal Current. Journal of Oceanography 64, 831-845.

Echevin V., 1998. Variabilité du niveau de la mer mesuré par altimetry dans le Golfe du Lion. Etude de l'influence de diverses observations sur la prévision de la circulation côtière. PhD manuscript, University of Toulouse.
Echevin, V., Mortier, L., Crépon, M., 2003. Interaction of a coastal current with a shelf topography, application to the Gulf of Lions shelf. Journal of Physical Oceanography 33, 188-206.

Estournel, C., Durrieu de Madron, X., Marsaleix, P., Auclair, F., Julliand, C., Vehil, R., 2003. Observation and modelling of winter coastal oceanic circulation in the Gulf of Lion under wind conditions influenced by the continental orography (FETCH experiment). Journal of Geophysical Research 108 (C3). doi:10.1029/2001JC000825.

Flexas, M.M., van Heijst, G.J.F., Jordà, G., Sánchez-Arcilla, A., 2004. Numerical simulation of barotropic jets over a sloping bottom: Comparison to a laboratory model of the Northern Current. Journal of Geophysical Research 109, C12039.

Font, J., Salat, J., Tintoré, J., 1988. Permanent features of the circulation in the Catalan Sea. Oceanologica Acta 9, 51-57.

Fu, L.L., Chelton, D.B., 2001. Large-scale ocean circulation. In: Fu, L.L., Cazenave, A. (Eds.), Satellite Altimetry and Earth Sciences. Academic Press, pp. 133-169.

García, E., Tintoré, J., Pinot, J.M., Font, J., Manriquez, M., 1994. Surface circulation and dynamic of the Balearic Sea. Seasonal and interannual variability of the Western Mediterranean Sea. Coastal and Estuarine Studies 46 (1994), 73-91.

Grilli, F., Pinardi, N., 1998. The computation of Rossby radii dynamical processes of deformation for the Mediterranean Sea. MTP News 6.

Herbaut, C., Mortier, L., Crépon, M., 1996. A sensitivity study of the general circulation of the western Mediterranean Sea: part I. The response to density forcing through the straits. Journal of Physical Oceanography 26 (1), 65-84.

Herbaut, C., Mortier, L., Crépon, M., 1997. A sensitivity study of the general circulation of the western Mediterranean. Part II: the response to atmospheric forcing. Journal of Physical Oceanography 27, 2126-2145.

Herbaut, C., Cordron, F., Crepon, M., 1998. Separation of a coastal current at a strait level: case of the strait of Sicily. Journal of Physical Oceanography 28, 1346-1362.

Jorda G., 2005. Towards data assimilation in the Catalan Continental Shelf From data analysis to optimization methods. PhD manuscript, university of Barcelona.

LeGrand, P., 2005. Future gravity missions and quasi-steady ocean circulation. Earth, Moon, and Planets 94 (1-2), 57-71. doi:10.1007/s11038-004-7606-9.

Legresy, B., Rémy, F., Blarel, F., 2006. Along track repeat altimetry for ice sheets and continental surface studies. ESA SP, Proceedings of the "15 years of satellite altimetry" conference, Italy. http://earth.esa.int/workshops/venice06/participants/181/ paper_181_legrsy.pdf.

Mangiarotti, S., Lyard, F., 2008. Surface pressure and wind stress effects on sea level change estimations from TOPEX/Poseidon Satellite Altimetry in the Mediterranean Sea. Journal of Atmospheric and Oceanic Technology, 25, pp. 464-474. http://dx doi.org/10.1175/2006JTECHO419.1.

Marullo, S., Santoleri, R., Bignami, F., 1995. The surface characteristics of the Tyrrhenian Sea: historical satellite data analysis. In: La Violette, P. (Ed.), Seasonal and Interannual Variability of the Western Mediterranean Sea: Am. Geophys. Union, Coastal and Estuarine Studies, 46, pp. 135-154.

Millot, C., 1987. Circulation in the western Mediterranean sea. Oceanologica Acta 10, $143-149$.

Millot, C., 1991. Mesoscale and seasonal variabilities of the circulation in the western Mediterranean. Dynamics of Atmospheres and Oceans 15 (3-5), 179-214.

Millot, C., 1995. PRIMO-0 and related experiments. Oceanologica Acta 18 (2), $137-138$.

Millot, C., 1999. Circulation in the Western Mediterranean Sea. Journal of Marine Systems $20,423-442$.

Morrow, R., Coleman, R., Church, J., Chelton, D., 1994. Surface eddy momentum flux and velocity variances in the southern ocean from Geosat altimetry. Journal of Physical Oceanography 24, 2050-2071.

Pascual, A., Nardelli, B.B., Larnicol, G., Emelianov, M., Comis, D., 2002. A case of an intense anticyclonic eddy in the Balearic Sea (western Mediterranean). Journal of Geophysical Research 107 (C11), 3183. doi:10.1029/2001JC000913.

Pinot, J.M., Tintoré, J., Gomis, D., 1995. Multivariate analysis of the surface circulation in the Balearic Sea. Progress in Oceanography 36, 343-376.

Pinot, J.M., López-Jurado, J.L., Riera, M., 2002. The Canales experiment (1996-1998). Interannual, seasonal and mesoscale variability of the circulation in the Balearic Channels. Progress in Oceanography 55, 335-370.

Poulain, P.M., 2008. Integration of Lagrangian observations into a Mediterranean marine observatory. In: Briand, F. (Ed.), Towards an integrated system of Mediterranean marine observatories, $n^{\circ} 34$ in CIESM Workshop Monographs. CIESM, Monaco. 144 pp.

Pujol, M.I., Larnicol, G., 2005. Mediterranean sea eddy kinetic energy variability from 11 years of altimetric data. Journal of Marine Systems 58, 121-142. doi:10.1016/j. jmarsys.2005.07.005.

Ridgway, K.R., Condie, S.A., 2004. The 5500-km-long boundary flow off western and southern Australia. Journal of Geophysical Research 109, C04017. doi:10.1029/ 2003JC001921.

Rio, M.H., Poulain, P.M., Pascual, A., Mauri, E., Larnicol, G., Santoleri, R., 2007. A mean dynamic topography of the Mediterranean Sea computed from altimetric data, in-situ measurements and a general circulation model. Journal of Marine Systems 65 (1-4), 484-508.

Rixen, M., Beckers, J.M., Levitus, S., Antonov, J., et al., 2005. The Western Mediterranean deep water: a proxy for climate change. Geophysical Research Letters 32, L12608. doi:10.1029/2005GL022702.

Roblou, L., Lamouroux, J., Bouffard, J., Lyard, F., LeHénaff, M., Lombard, A., Marsaleix, P., DeMey, P., Birol, F., in press. Post-processing altimeter data toward coastal applications and integration into coastal models. Coastal Altimetry. Chapter 8 , Springer Verlag Book.

Rubio, A., Arnau, P.A., Espino, M., Flexas, M.M., Jordà, G., Salat, J., Puigdefàbregas, J., Arcilla, A.S., 2005. A field study of the behaviour of an anticyclonic eddy on the Catalan continental shelf (NW Mediterranean). Progress in Oceanography 66, 142-156. 
Sammari, C., Millot, C., Prieur, L., 1995. Aspects of the seasonal and mesoscale variabilities of the Northern current in the western Mediterranean Sea inferred from the PROLIG-2 and PROS-6 experiments. Deep-Sea Research I 42 (6), 893-917.

Send, U., Font, J., Krahmann, G., Millot, C., Rhein, M., Tintoré, J., 1999. Recent advances in observing the physical oceanography of the western Mediterranean Sea. Progress in Oceanography 44, 37-64.

Strub, P.T., James, C., 2002a. Altimeter-derived surface circulation in the large-scale NE Pacific Gyres. Part 1. Annual variability. Progress in Oceanography 53 (2-4), 163-183.

Strub, P.T., James, C., 2002b. Altimeter-derived surface circulation in the large-scale NE Pacific Gyres. Part 2. 1997-1998 El Niño anomalies. Progress in Oceanography 53 (2-4), 185-214.

Tintoré, J., Ping-Wang, D., La Violette, P., 1990. Eddies and thermohaline intrusions of the shelf/slope front off the north-east Spanish coast. Journal of Geophysical Research 95 (C2), 1627-1633.
Vignudelli, S., Gasparini, G.P., Astraldi, M., Schiano, M.E., 1999. A possible influence of the North Atlantic Oscillation on the circulation of the Western mediterranean Sea. Geophysical Research Letters 26 (5), 623-626.

Vignudelli, S., Cipollini, P., Roblou, L., Lyard, F., Gasparini, G.P., Manzella, G., Astraldi, M., 2005. Improved satellite altimetry in coastal systems: case study of the Corsica Channel (Mediterranean Sea). Geophysical Research Letters 32, L07608. doi:10.1029/ 2005GL022602.

Volkov, D.L., Larnicol, G., Dorandeu, J., 2007. Improving the quality of satellite altimetry data over continental shelves. Journal of Geophysical Research 112. doi:10.1029/ 2006JC003765

Wang, L., Koblinsky, C.J., 1996. Annual variability of the subtropical recirculation in the North Atlantic and North Pacific: a TOPEX/Poseidon Study. Journal of Physical Oceanography 26 (11), 2462-2479. 